Charity Auctions: A Field Experimental Investigation

by

Jeffrey Carpenter

Jessica Holmes

Peter Hans Mattahews

September 2004

MIDDLEBURY COLLEGE ECONOMICS DISCUSSIO N PAPER NO. 04-17

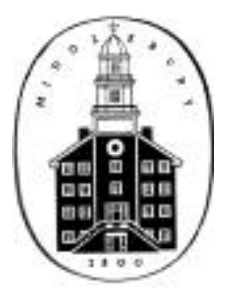

DEPARTMENT OF ECONOMICS

MID DLEBURY COLLEGE

MIDDLEBURY, VERMONT 05753

http:// www.middlebury.edu/ econ 


\title{
Charity Auctions: A Field Experimental Investigation*
}

\author{
Jeffrey Carpenter ${ }^{\dagger}$ Jessica Holmes ${ }^{\ddagger}$ Peter Hans Matthews ${ }^{\S}$
}

September 15, 2004

\begin{abstract}
Auctions are a popular way to raise money for charities, but relatively little is known, either theoretically or empirically, about the properties of charity auctions. The small theoretical literature suggests that the all-pay auction should garner more money than winner-pay auctions. We conduct field experiments to test which sealed bid format, first price, second price or all-pay raises the most money. Our experiment suggests that both the all-pay and second price formats are dominated by the first price auction. Our design also allows us to identify differential participation as the source of the difference between existing theory and the field. To conclude, we show that a model of charity auctions augmented by an endogenous participation decision predicts the revenue ordering that we see in the field.
\end{abstract}

\section{Introduction}

For a period of time after Vickrey's (1961) seminal contribution to the literature, the Revenue Equivalence Theorem remained the point of departure for most formal discussions of private value auctions, despite mixed empirical evidence from both the field (Laffont, 1997) and the experimental lab (Kagel, 1995). As the recent surveys of Klemperer (1999), Krishna (2002) and others evince, however, attention has shifted over the last decade or two, toward a fuller characterization of those environments in which revenue equivalence is not expected to hold. One of the most important of these is the case of "price proportional benefits," as Engelbrecht-Wiggans (1994) first called them, in which auction losers also derive some benefit, one that is proportional to either the winner's bid or, in

*We thank Zafreen Syed and Marla Weinstein for research assistance and Yan Chen, Carolyn Craven, Steve Holmes, Rob Moir, and Corinna Noelke for valuable comments. We also acknowledge the financial support of Middlebury College and the National Science Foundation (SES-CAREER 0092953).

†Department of Economics, Middlebury College and IZA, Bonn; jpc@middlebury.edu.

$\ddagger$ Department of Economics, Middlebury College; jholmes@middlebury.edu.

$\S$ Department of Economics, Middlebury College; pmatthew @middlebury.edu 
the more general case, total revenues. The most familiar example of this is perhaps the charity auction, but the list includes the use of auctions or lotteries to finance the provision of public goods and some forms of bidder cartels. Jehiel, Moldovanu and Stacchetti (1996) have even extended this framework to allow for individual-specific externalities and use it to discuss the sale of nuclear weapons.

Our immediate concern in this paper is the proposition (Engers and McManus, 2002; Goeree, Maasland, Onderstal and Turner, 2004) that charities will do better with "all-pay" than any other form of "winner pay" auction. In particular, we report on the results of a field experiment conducted at local (Addison County, Vermont) preschools that allow us to estimate the determinants of individual behavior and total revenue in three sorts of sealed bid auctions, the first price, second price, and all-pay. We find that the all-pay does not revenue dominate the others, and that the principal reason for this is the differential effect of auction format on participation, an important practical consideration in the field. To advance theory in light of our experimental results, we also offer a model of charity auctions that allows for endogenous participation and show that such a model captures much better the revenue differences we see in the field.

We are not the first to collect experimental data on individual behavior and total revenue in auctions for charities but there are, as far as we know, no other studies that compare these three mechanisms in the field and allow for nonparticipation. For example, Davis et al. (2003) conduct a lab experiment in which lotteries produce more revenues than English auctions, and find that this result is robust with respect to the distribution of private values, the rate of return on the local public good or repeated play, consistent with the previous work of Morgan and Sefton (2000). Inasmuch as lotteries can be viewed as an inefficient variation of the all-pay mechanism - the bidder who purchases the most tickets becomes the most probable winner - this is consistent with the spirit of Engers and McManus (2002) and Goeree at al (2004). Goeree and Schram (2004) provide more direct support for this result: their experiment, which relies on altruistic private values induced in the lab, compares the first price, all-pay and lottery mechanisms, and finds that all-pays revenue dominate lotteries, and that lotteries revenue dominate first price auctions. The difference between the Davis et al (2003) or Goeree and Schram (2004) results and ours, we believe, reflects the existence of a more complicated participation calculus in the field. In Orzen (2003), which Goeree and Schram (2004) cite, lotteries and two variations of the all-pay are compared but, in this experiment, values are common not private. Last, Isaac and Schneir (2003) use the lab to testbed features of the silent auction, another format commonly used for charitible fundraising.

In the next section, we review a special case of the Engers-McManus model, with emphasis on the comparative statics of optimal bids and expected revenues across mechanisms, and discuss some of the possible consequences of endogenous participation. We describe our experimental protocol in the third section, a protocol that allows us to collect more than the usual amount of data, not least 
a measure of private value, on all potential (that is, active and inactive) bidders. The fourth section summarizes the field data and reports our estimates of various revenue and bid functions. We conclude in the fifth section by highlighting the importance of participation both as a practical matter by estimating the lost revenues associated with each auction format due to reduced participation, and as a theoretical matter by integrating a number of recent models.

\section{Expected Auction Outcomes and Economet- ric Specifications}

It should come as no surprise that the predictions of either the Engers and McManus (2002) or Goeree et al (2004) models should be difficult to substantiate outside the experimental lab: both assume that private values can be modelled as independent draws from some common distribution function, that the number of active bidders is predetermined and known to all, and that each of these otherwise identical bidders is risk neutral. In addition to the revenue proportional benefits that accrue to all the bidders, Engers and McManus (2002) allow winners to experience an additional "warm glow" (Andreoni, 1989), with minimal consequences.

To understand some of the possible econometric implications, consider the special case in which private values are drawn from a uniform distribution over the interval $[0, \bar{v}]$, and all $N$ bidders receive a benefit $0 \leq \alpha<1$ for each dollar of revenue. It is then not difficult to show ${ }^{1}$ that the optimal (symmetric) bid functions $B^{k}(v), k=F($ irst price), S(econd price), $A(l l-p a y)$, and the resultant expected revenues $R^{k}$, will be:

$$
\begin{aligned}
B^{F}(v) & =\frac{N-1}{N-\alpha} v \\
B^{S}(v) & =\frac{\alpha \bar{v}+v}{1+\alpha} \\
B^{A}(v) & =\frac{N-1}{N} \frac{1}{1-\alpha}\left(\frac{v}{\bar{v}}\right)^{N-1} v
\end{aligned}
$$

and:

$$
\begin{aligned}
R^{F} & =\frac{N(N-1)}{(N-\alpha)(N+1)} \bar{v} \\
R^{S} & =\frac{(N-1+\alpha(N+1))}{(1+\alpha)(N+1)} \bar{v} \\
R^{A} & =\frac{(N-1)}{(1-\alpha)(N+1)} \bar{v}
\end{aligned}
$$

\footnotetext{
${ }^{1}$ The details of a generalized model are presented in Appendix A.
} 
In the familiar case where $\alpha=0$, bidders in the first price shade their bids a fraction $\frac{N-1}{N}$ beneath their private values, bidders in the second price auction bid their values, and bidders in the all-pay auction bid a fraction $\frac{N-1}{N} s^{N-1}$ of their values, where $s=\frac{v}{\bar{v}}$ is the expected proportion of bidders with lower values, and revenue equivalence obtains, with $R^{k}=\frac{N-1}{N+1} \bar{v}$ for all $k$.

When there is a public goods aspect to bidding, it is not difficult to see that as the number of bidders increases, the difference between expected revenues in the second and first price auctions tends to zero - with a common limit that is independent of $\alpha$ - but that both produce less revenue than the allpay: $\lim _{N \rightarrow \infty} R^{F}=\lim _{N \rightarrow \infty} R^{S}=\bar{v}$, but $\lim _{N \rightarrow \infty} R^{A}=\frac{\bar{v}}{1-\alpha}$. This result, it should be added, is robust with respect to the choice of distribution functions. But should charities be able to count on the "all-pay premium" with finite, even small, numbers of bidders? The answer is yes, almost. A little algebra reveals that in the uniform case, $R^{A}$ will exceed both $R^{S}$ and $R^{F}$ when $N \geq$ 3 , no matter what the return on charitable donations. Furthermore, some experimentation with alternative (but plausible) distributions hints that this low threshold is not an artifact. No less important, first and second price auctions are not revenue equivalent for finite $N$ : with small numbers of bidders, charities should robustly prefer the latter. Existing theory then suggest the following (conditional) ordering:

$$
R^{A}>R^{S}>R^{F}
$$

for fixed $N, \alpha$ and $\bar{v}$.

An increase in the number of bidders will increase expected revenue under all formats - that is, $\frac{d R^{k}}{d N}>0$ for all $k$ - but the size of this effect is specific to each. On the basis of the above mentioned properties - in particular, the fact that the first price "catches up" to the second price as $N$ increases, but that neither catches up to the all-pay - it seems reasonable to speculate that:

$$
\frac{d R^{A}}{d N}>\frac{d R^{F}}{d N}>\frac{d R^{S}}{d N}>0
$$

This is indeed the case, but numerical methods reveal that in practice, the derivatives are often close in value.

To incorporate some mechanism-specific effects into our econometric specifications, we use a number of interaction variables. The first terms in our simple model of the observed revenue $R_{j}$ for object $j$, for example, would assume the form:

$R_{j}=\beta_{0}+\beta_{1} A P_{j}+\beta_{2} F P_{j}+\beta_{3} N_{j}+\beta_{4}\left(A P_{j} \times N_{j}\right)+\beta_{5}\left(F P_{j} \times N_{j}\right)+\beta_{6} \alpha \ldots+u_{j}$

where $A P_{j}$ and $F P_{j}$ are format indicators, $N_{j}$ is the number of bidders, and the second price auction is the default. In our case, $N_{j}$ was defined to be the mean, over all participants, of the expected number of bidders, and not their actual number, which no one knew at the time bids were made. The first, and most 
important, prediction of the model, that $R^{A}>R^{S}>R^{F}$, then corresponds to the null:

$$
\beta_{1}+\beta_{4} N_{j}>0>\beta_{2}+\beta_{5} N_{j}
$$

Likewise, the prediction that $\frac{d R^{A}}{d N}>\frac{d R^{F}}{d N}>\frac{d R^{S}}{d N}>0$ becomes the null $\beta_{3}, \beta_{4}$, $\beta_{5}>0$ and $\beta_{4}>\beta_{5}$.

An increase in the return on charitable donations will also increase expected revenues under all three formats $\left(\frac{d R^{k}}{d \alpha}>0\right)$. However, the magnitiude of this effect is difficult to order among the three formats and therefore we only include the baseline effect in our analysis (i.e., $\beta_{6}>0$ ).

There are at least four features of the optimal bid functions with important econometric implications. The first is of course the size of the bids themselves. It is not difficult to show that in the uniform case, $B^{S}(v)>B^{F}(v)$ for all $\alpha$ and $N$ - the feature is in fact a robust one - and the intuition is the same as it is in the no spillover case: bidders in first-price charity auctions are still able to shade their bids. To most casual observers, it seems obvious that when all participants forfeit their bids, bid values will be lower than either winner-pay format. Obvious, perhaps, but not (quite) correct. For small $N$ and substantial $\alpha$, very high value bidders will sometimes bid more in the all-pay than either of the winner-pays. ${ }^{2}$ It is nevertheless the case that for almost all bidders in realistic auctions, the order will be:

$$
B^{S}(v)>B^{F}(v)>B^{A}(v)
$$

with the caveat that as private value $v$ increases, the differential between $B^{S}(v)$ or $B^{F}(v)$ and $B^{A}(v)$ narrows. To provide some sense of the numbers, for $N=10, \bar{v}=50$ and $\alpha=0.20$, the median bidder $(v=25)$ will bid 41.7 in the second price, 36.8 in the first price and just 0.05 in the all-pay, and even for a bidder whose private value is at the 90 th percentile $(v=45)$, the bids are 45.8 , 41.3 and 19.6, respectively.

We know that bids will be monotone functions of private value but the relative sizes of this effect are less clear. In the uniform case, it can be shown that $\frac{d B^{F}}{d v}>\frac{d B^{S}}{d v}$ whenever $\alpha N>1$ or, in other words, when the number of bidders exceeds some threshold, but also that the difference between them often tends to be small in practice. The response of all-pay bidders is more complicated, however: it is much smaller (close to zero, in fact) than both $\frac{d B^{F}}{d v}$ and $\frac{d B^{S}}{d v}$ for small private values, but eventually increases and becomes larger than both. Given these uncertainties, the second of the features we are interested in is just $\frac{d B^{k}}{d v}>0$ for all $k$.

The response of individual bidders to variations in the number of participants or rivals, the third feature, would seem to offer a straightforward test of the model, since:

\footnotetext{
${ }^{2}$ The details of this phenomenon appear in Appendix A.
} 


$$
\frac{d B^{A}(v)}{d N}<\frac{d B^{S}(v)}{d N}=0<\frac{d B^{F}(v)}{d N}
$$

for all reasonable values of $\alpha$ and $N .^{3}$ Both $\frac{d B^{F}(v)}{d N}$ and $\frac{d B^{A}(v)}{d N}$ tend to zero as $N$ increases and $\frac{d B^{S}(v)}{d N}=0$. This feature is not specific to charity auctions, however: even when the rate of return on charitable donations is zero $(\alpha=0)$, bidders in second price auctions find it dominant to bid their values whether there are one, or one million, other bidders, those in first price auctions cannot afford to shade their bids as much as the number of other bidders rises, while competition increases the likelihood that those in all-pay auctions will forfeit their bids.

Last, consistent with intuition, it will be the case that $\frac{d B^{k}}{d \alpha}>0$. That is, bids will increase with one's attachment to the charity but the effect varies across mechanisms, with no definite size order in either theory or practice.

As the fourth section describes in more detail, we will estimate both participation and, conditional on this, bid values, but the latter will resemble:

$$
B_{i, j}=\tau_{0}+\tau_{1} A P_{j}+\tau_{2} F P_{j}+\tau_{3} N_{i, j}+\tau_{4}\left(A P_{j} \times N_{i, j}\right)+\tau_{5}\left(F P_{j} \times N_{i, j}\right)+\tau_{6} v_{i, j}+\tau_{7} \alpha_{i}+\ldots+\epsilon_{i, j}
$$

where $i$ refers to individuals and $j$ still indexes objects. The first feature (that bids are ordered $\left.B^{S}(v)>B^{F}(v)>B^{A}(v)\right)$ now corresponds to the null:

$$
0>\tau_{2}+\tau_{5} N_{i, j}>\tau_{1}+\tau_{4} N_{i, j}
$$

and the second (that $\frac{d B^{k}}{d v}>0$ for all $k$ ), to $\tau_{6}>0$. The third $\left(\frac{d B^{A}(v)}{d N}<\right.$ $\left.\frac{d B^{S}(v)}{d N}=0<\frac{d B^{F}(v)}{d N}\right)$, on the other hand, translates into $\tau_{3}=0, \tau_{3}+\tau_{4}<0$ and $\tau_{3}+\tau_{5}>0$ and the fourth $\left(\frac{d B^{k}}{d \alpha}>0\right)$ implies $\tau_{7}>0$.

All of this said, the most important of these predictions, both from our perspective and that of the charities themselves, is the existence of an all-pay revenue premium. The standard model assumes, however, that the number of participants $N$ is fixed and known to all, and this was not the case in our field experiments. In particular, not all who attended the fundraisers or, for that matter, bid on one of the items, chose to bid on all of them. Furthermore, those who submitted bids did not, and could not, know the number of other active bidders, and there was wide variation in their estimates of this number. Potential bidders behaved, in other words, as if there were transactions cost associated with participation, the effect of which is to endogenzie the number of active bidders. ${ }^{4}$

\footnotetext{
${ }^{3}$ For bidders with private values close to the maximum, $\frac{d B^{A}(v)}{d N}$ can be positive for small $N$.

${ }^{4}$ Some of these costs seemed to be common to all three formats, but some did not. On the one hand, participants needed to wait until the end of the fundraiser to be told the results, and those who came with small children sometimes found it difficult to prepare a bid, for reasons that the next section will make clear. On the other, the rules of the all-pay and, to a lesser extent, the second price auctions seemed obscure to some bidders, so that the cognitive costs of submitting a sensible bid differed. Furthermore, at least some potential bidders
} 
Given the fact that we were unable to detect such a premium - in fact, as the fourth section details, the all-pay format seemed to impose a "revenue penalty" - the question is whether or not this is the result of the participation decisions of individual bidders. The issue is critical not just to charities, but also to experimentalists because subjects in the field can often choose not to participate. Until recently, however, the theoretical implications of endogenous participation were not well understood. Building on the previous work of Samuelson (1985) and Stegeman (1996), Menezes and Monteiro (2000) consider an otherwise standard private values model in which each bidder knows the number of potential bidders but must decide whether the expected benefits of participation exceed some fixed cost. In both the first and second price auctions (the all-pay is not considered) bidders follow a simple cut off rule: those with private values below some threshold, the value of which is common to the two mechanisms, do not participate. Menezes and Monteiro (2000) find that under these conditions, revenue can sometimes decrease as the number of potential bidders rises because competition also causes the participation threshold to rise. However, they also find that the first and second price auctions remain revenue equivalent. We show, by way of example, that this equivalence extends to the all-pay format.

If, following Goeree et al (2004), the introduction of a spillover effect priviliges the all-pay, but if, following Menezes and Monteiro (2000), revenue equivalence is preserved in the absence of such spillovers, it seems, at first blush, that participation costs cannot explain our field data. As the hybrid model we describe in the fifth section demonstrates, however, this conclusion is premature. We find, in fact, that our data are consistent with the view that charities who want to maximize the proceeds of their auctions must carefully consider the relationship between format and participation.

\section{Experimental Procedures}

We decided to conduct our experiment in the field after weighing the costs and benefits of doing so. One factor that we considered to be a major benefit of a field implementation is that we were able to identify a population for whom bidding in our auctions would be saliently interpreted as an act of charity. We decided that examining behavior in this population could ensure the external validity of our results. Instead of inducing charitable preferences (a la Goeree and Schram, 2003 and Davis et al, 2003) in traditional lab participants, we recruited participants who had naturally occurring altruistic preferences for the beneficiaries of our auctions. At the same time, however, relying on naturally occurring altruistic preferences means that we did not induce valuations for the items auctioned. At first blush, this appears to be a cost of our field protocol because it hinders the analysis of efficiency, but we felt this cost would be small given other features of our procedures that we detail below.

voiced strong feelings about the all-pay format. One such bidder, for example, read the rules, discussed them with one of us and returned some time later to complain that it seemed to him a bad (inefficient?) sort of lottery! 
While plenty of auction experiments have been conducted successfully in the field despite the drawback of not knowing bidder valuations (e.g., LuckingReiley, 1999 or List and Lucking-Reiley, 2000), we advance the literature and partially solve this problem by collecting demographic and attitudinal data from our participants that provides us with many of the correlates of individual private values. For example we asked for two direct measures of their values on each item they bid and, because the surveyed values were noisy, we also gathered data on family income as a proxy for a bidder's private value. We also gathered information on bidder's attachment to the preschool including the number of children years (i.e., the total number of years a bidder's child or children will be or have been at the preschool) and recent donations to the preschool as proxies for $\alpha$, the public good aspect of revenue.

There are other aspects of our design that we consider to be improvements over past experiments. In addition to collecting bids, we also had as many of the attendants of the event as possible fill out our survey, regardless of whether they bid on items or not. This survey allows us to control for demographic differences in our populations that may affect bidding behavior when we test for differences in our auction formats. Unlike other auction experiments in the lab or in the field that only collect positive bids, we collected all the bids, even if they were for $\$ 0$. We think this is a subtle, but significant contribution of our field protocol. Our intuition was that subjects come to the lab "ready to play" and are, therefore, much less likely to withdraw and not bid in an auction than they would be outside the lab in a more natural setting.

Together, the bid data and the survey data allow us to directly examine participation in our auctions. We anticipated that selection and participation might be important factors that have been neglected to this point. Allowing participation to be endogenous adds another dimension to the revenue properties of different auction institutions. If one auction type discourages participation (perhaps because the institution seems complicated or too unfamiliar), and if the resulting selection of bidders affects the revenue collected in the auction, then auction formats may affect revenues both through bidding behavior and through the effects of the institution on participation.

\subsection{Our Field Implementation}

Each spring, the preschools in Addison County conduct fund-raising festivals. In the spring of 2003, four of these preschools agreed to augment their festivals with charity auctions that we conducted. These fund-raisers are traditionally attended mostly by parents, other family members, and employees and board members of the schools. This fact implies that the attendees had some altruistic connection to the school and viewed the money raised by our auction as a public good benefiting their school. Because these auctions were part of the normal spring fund-raising activities of the schools, we consider our implementation to be a natural field experiment in which the subjects undertook a familiar task (defined broadly as fund-raising) in a familiar setting and did not necessarily 
know that they where participating in an experiment. ${ }^{5}$

\subsection{Auction Details}

We conducted four sealed bid auctions at four different preschools in the months of May and June. The format of the auction was unknown to the participants before the day of the event. There was one first price auction, one second price auction and two all-pay auctions. We conducted two all-pay auctions because the first price and second price auctions were relatively well attended, but our first all-pay auction fell on a rainy day which reduced attendance. Therefore we conducted another all-pay auction at a different preschool to make the overall number of bidders in each format more comparable. While we conducted only four auctions, our sample size, for revenue purposes, is 80 because during each session we auctioned off the same 20 items that varied in retail value. Table 1 provides the descriptions and retail values of the 20 items we sold at each auction. The items vary from children books and games to gift certificates for services that parents typically need (auto detailing) or want (a vacation at a local spa) with retail values varying from $\$ 10$ to $\$ 275 .{ }^{6}$ We spent considerable energy deciding on the mix of goods to sell and felt that including variation in the retail value and the type of good would not only appeal to a wide variety of bidders, it would also sharpen our subsequent analysis.

The exact procedures we used are as follows. When attendees arrived at the festival they were given a survey (see Appendix B) to fill out. Completed surveys were collected at our auction station. When each attendee was finished with his or her survey, $\mathrm{s}(\mathrm{he})$ was given a "bid kit." In each bid kit we placed a set of instructions for the auction and cards for each of the 20 items (see Appendix B for an example). Each item was displayed on a table with its retail value and a full description. Participants typically spent twenty or thirty minutes inspecting the items and filling out their bid kits. On each bid card we asked participants four questions in addition to asking them for their bids. We asked them whether they would buy the item in a store and how much they would pay for the item in a store, how much they would bid for the item in a for profit auction, and the sex of the bidder. The first three questions provide us with information on the individual's private value for the item. We asked the participants to fill out each bid card completely, even if they decided to bid $\$ 0$ for the item.

As they were completed, bidders turned in their bid kits to one of the auctioneers who matched the bid kit number to the bidder's survey and gave the bidder a small slip of paper with the bidder's identification number on it. In each auction there was a predetermined time at which we stopped accepting

\footnotetext{
${ }^{5}$ See Carpenter et al. (2004) for a more detailed discussion of the taxonomy of field experiments.

${ }^{6}$ The potential problem with selling gift certificates is that these items might have common value properties. However, we realized that the possibility of a secondary resale market evolving was extremely small and all the certificates were for local services that bidders would have surely formed private values for (e.g., not everyone loves the pizza at our local pizzeria).
} 
bids. After this time, we privately sorted the bids into twenty piles and determined the highest (winning) bid for each item. We selected one winning bid at random in the few cases in which there were ties. This process typically took half an hour. When all the winning bids were determined, we gathered the bidders, announced the winner of each item, and collected payments (except in the all-pay auctions where we collected payments when bidders turned in their bid kits). Winning bidders wrote checks directly to the preschool benefiting from the auction.

\section{Experimental Results}

Table 2 presents a comparison of the summary statistics by auction. Revenues varied from a low of $\$ 656$ in all-pay auction (2) to a high of $\$ 1226$ in the first price format. The number of potential participants varied from 15 in all-pay (1) to 31 in the first price auction. We gathered bids from more attendees in the first price and second price auctions than in both all-pay auctions where participation was more limited. As mentioned above, the turn out for all-pay (1) led us to conduct all-pay (2) which did draw many more attendees, but as one can see in Table 2, participation in an auction format is a separate issue from the number of attendees. As we will explore in more detail later, average participation rates, defined as the number of potential bidders who actually submitted a positive bid on a given item, were quite low in the all-pay auctions (about 14\%) compared to the second price (39\%) and first price (53\%) formats. One last comparison worth highlighting involves the socioeconomic status of the auction guests; the proportion of participants in the lowest income bracket was notably higher in all-pay auction (1) $(73 \%)$ than in any of the other three auctions.

\subsection{Revenue}

Returning to Table 1, we now consider the revenue generated by item and auction. The first price auction generated the greatest total revenue $(\$ 1226)$, followed by all-pay auction (1) (\$904), the second price auction $(\$ 825)$, and lastly, all-pay auction (2) $(\$ 656)$. Revenue comparisons by item further reveal that the first price auction earned the highest revenue (among all four auctions) for eleven of the twenty items.

To test the notion of revenue equivalence while controlling for confounding factors, we use ordinary least squares to estimate the determinants of revenue in Table 3. Robust standard errors are corrected for non-independence of the error terms within auctions. Column (1) presents a basic revenue model that includes dummies for auction format (second price is the omitted category), the average expected number of bidders per item, and retail value and its square. This simple model explains $54 \%$ of the variation in revenue. In accordance with our hypotheses from section 2, column (2) extends the basic model by incorporating interactions between auction type and the average expected number of bidders, 
as well as, controls for the demographic characteristics of the bidders and their average private values. ${ }^{7}$ The more elaborate specification explains more than $60 \%$ of the variation in revenue.

The results suggest that when one considers mechanism only, the first price auction revenue-dominates the second price auction, with no significant difference between all-pay and second-price formats. ${ }^{8}$ However, the significance of both interaction terms in column (2) suggests a differential impact of bidder competition by auction type; specifically, we find that each additional expected bidder lowers revenue by $\$ 1.58$ in the all-pay and $\$ 0.22$ in the first price format, but increases revenue by $\$ 0.83$ in the second-price format. Not surprisingly, the results in the full model suggest a positive and significant (non-linear) relationship between revenue per item and retail value; a $\$ 1$ increase in retail value generates nearly $\$ 0.90$ in additional revenue for the seller. Collectively, the demographic characteristics of bidders play only a minor role in revenue generation. However, average future child-years at the preschool, as a proxy for $\alpha$, does have a significant effect on revenue (and the effect is quite large); an increase by one in the bidders' average number of future child-years is associated with an additional $\$ 12$ in revenue. This supports our expectation that revenue increases when participants have stronger attachment to the charity.

The model presented in section 2 predicted that revenue would be ordered, $R^{A}>R^{S}>R^{F}$, if the auction attendees considered the revenues from our auction to be a public good. Instead, based on Table 3 , we find that $R^{F}>$ $R^{A}=R^{S}$ indicating that charities raise the most revenue by using the first price format and not the all-pay format. ${ }^{9}$ We also see that while the size of the bidding population matters, it does not matter in the way predicted by theory. Instead of the all-pay for mat taking the most advantage of the behavior of each additional bidder (i.e., our expectation was $\frac{d R^{A}}{d N}>\frac{d R^{F}}{d N}>\frac{d R^{S}}{d N}$ ), we find that additional bidders actually reduce the revenue collected in the all-pay and first price auctions. ${ }^{10}$ However, we do confirm that increasing the number of expected bidders in the second price auction does not affect revenues. Lastly, as mentioned in the previous paragraph, we do find limited support for the prediction that revenues will increase in bidders attachment to the charity. ${ }^{11}$

\subsection{Efficiency}

An advantage of our design is that we collected information on our participant's private values (proxied here by the maximum of either the amount one would

\footnotetext{
${ }^{7}$ Due to the inclusion of demographic characteristics of the bidders in column (2) and the desire for comparability across the two models, the six items that earned zero revenue were excluded from both regressions. Note however, that when these six items are included in the model without demographic characteristics our results do not qualitatively differ from those reported in column (1).

${ }^{8}$ In addition, the all-pay and first price point estimates are not significantly different.

${ }^{9}$ Specifically, we find $\beta_{2}+\beta_{5}>\mathbf{0}, \beta_{1}+\beta_{4}$ is not significantly different from zero, and $\beta_{2}=\beta_{1}$.

${ }_{10}$ That is, although $\beta_{3}>\mathbf{0}$ as predicted, we find that $\beta_{4}, \beta_{5}<\mathbf{0}$.

${ }^{11}$ Specifically, $\beta_{6}$ is greater than zero for one of our proxies, future child years.
} 
pay for the item in a store or the amount one would bid for the item in a non-charity auction) and, therefore, we can discuss the efficiency properties of our three auction formats. A review of our auctions and items suggests that first-price and all-pay auctions are generally more efficient than second price auctions. Controlling for the expected number of bidders, and the item's retail value and its square, a simple probit analysis of the determinants of efficiency confirms this pattern (Table 4). Specifically, column (1) suggests that compared to second price auctions, items are $9 \%$ more likely to be allocated efficiently in an all-pay auction and $32 \%$ more likely to be allocated efficiently in a first price auction. Furthermore, we can reject the null hypothesis that the coefficients on all-pay and first-price are equal $(p<0.01)$, suggesting that first price auctions are the most efficient format. These results are robust to the deletion of the six all-pay items that garnered no revenues. In this case. column (2) suggests that the relative efficiency of the all-pay mechanism increases but the all-pay is still significantly less efficient than the first price auction $(p<0.05)$. Interestingly, an increase in the average number of expected bidders decreases the probability that the winner is also the individual with the greatest private value; specifically, each additional (expected) bidder decreases the probability of an efficient auction outcome by between two and three percent.

While the standard definition of efficiency is of allocative interest, an alternative measure, based on the proportion of the retail value of the items that is recovered, might be more important to charities. ${ }^{12}$ Returning to Table 1 , we see that the first price auction recovered $98 \%$ of the retail value of the items we auctioned, while the other three auctions recovered only $66 \%$ in the second price, $72 \%$ in the first all-pay and $52 \%$ in the second all-pay. The first price auction is also more efficient using this more practical measure.

\subsection{Bid Functions}

Since many observable factors (e.g., auction type, expected number of bidders, household income, private value) are likely to influence both the decision to participate in an auction and one's bid, it is possible that the unobservable determinants of both outcomes are also related. If so, then the correlation between the errors in the participation and bid equations will lead to sample selection bias when the determinants of bid outcomes are estimated for participants only. However, if the correlation between the two errors is zero, then bid outcomes can be estimated conditional on participation without concern that sample selection will bias the coefficients. Using a selection model (Heckman, 1979) in Appendix $\mathrm{C}$, we find that once we control for private valuations, there is no evidence that the sample of individuals who submit bids is systematically different from those who do not, and thus report separate probit estimates of the determinants of participation and ordinary least squares estimates of bid value (conditional on participation).

Table 5 presents the marginal effects from probit estimations of the determi-

\footnotetext{
${ }^{12}$ We thank Rob Moir for making this suggestion.
} 
nants of participation. The model in column (1) incorporates information on auction type, expected number of bidders, private value (proxied by the maximum one would pay in a store for the item or the amount one would bid in a non-charity auction), retail value and its square, and the demographic characteristics of the bidder (i.e., gender, income, future child-years at the preschool, recent donations to the preschool, and employee/board member status). The more elaborate model in column (2) adds interactions between auction type and expected number of bidders. Robust standard errors are corrected for within bidder correlation in both models. In general, the qualitative results are similar across the models, so in what follows, we report the results of the more elaborate model in column (2).

Our key finding is that auction type has a significant effect on the decision to submit a bid; that is, ceteris paribus and relative to second price auctions, bidders are $26 \%$ more likely to participate in first-price auctions and $15 \%$ less likely to participate in all-pay auctions. We attribute this to the relative familiarity of the first-price mechanism and the uncertainty associated with the less common second and all-pay formats. Furthermore, as the expected number of bidders increases, the more likely an individual will bid, but this effect is dampened in both the all-pay and first-price formats (i.e. the interaction terms suggest that there is a differential effect of expected bidders by auction-type). In particular, we find that the expectation of one additional bidder increases the probability of submitting a bid by $0.3 \%$ in the first-price, $0.4 \%$ in the all-pay and $1 \%$ in the second price. Individuals with higher private values, employees, and members of the school boards are all more likely to participate: an increase of $\$ 10$ in private value is associated with a $2 \%$ increase in the likelihood of participation, ${ }^{13}$ and employees and board members are $21 \%$ more likely to participate. The last effect may be the result of peer pressure.

Lastly we find evidence that attachment to the public good plays an important role in the participation decision. For example, females are $13 \%$ more likely than either males or couples to bid and we speculate that this reflects a stronger attachment (due perhaps to greater exposure) to the preschool. While a bidder's previous money donations to the preschool significantly decrease the probability of participation, the small size of the coefficient calls into question the economic significance of this (perhaps) counterintuitive result. ${ }^{14}$ Bidders with householdincomes less than $\$ 75,000$ are almost $10 \%$ less likely to participate (relative to those with incomes greater than $\$ 125,000$ ).

Table 6 presents the results of an ordinary least squares estimation of the determinants of bid value (conditional on participation). Again, column (1) presents a simple model that incorporates information on auction type, expected number of bidders, retail value and its square, private value, and the demographic characteristics of the bidder while the more elaborate model in column (2) adds interactions between auction type and expected number of

\footnotetext{
${ }^{13} \mathrm{It}$ is interesting to note that the model presented in Section 5.2 (and Appendix A) predicts participation will be increasing in both $\bar{v}$ and $v$.

${ }^{14}$ An alternative interpretation is that previously generous bidders feel "tapped out" and are less likely to participate in the auction.
} 
bidders. Robust standard errors are corrected for within bidder correlation in both models.

The results in column (1) suggest that bids in the all-pay are significantly less than those in second price and even first-price auctions $(\mathrm{p}<0.01)$. However, inclusion of the interaction between auction format and expected number of bidders in column (2) suggests that the negative relationship between all-pay format and bid value is really due to the strong negative effect that perceived competition has on one's bid; taking the baseline and interaction terms together, we see that each additional expected bidder is associated with a reduction in one's bid of $\$ 0.19$ in the all-pay and $\$ .004$ in the first-price but an increase in one's bid of $\$ 0.23$ in the second price for mat. Retail value has a positive effect on bids (although the relationship is non-linear) suggesting that an increase in retail value by $\$ 1$ is associated with an approximate $\$ 0.40$ increase in bid. Furthermore, even after controlling for retail value, we find that bids increase by $\$ 0.21$ for every $\$ 1$ increase in private value. As expected, socioeconomic status has a significant effect on bid value; members of households with less than $\$ 75,000$ annual income submit bids that are about $\$ 9$ lower than otherwise similar bidders from households that earn more than $\$ 125,000$ yearly (the omitted category). Lastly, each previous dollar donated to the preschool is associated with a $\$ .03$ increase in bid.

Reconciling our empirical and theroetical resulst, we find more support for theory, although not all the hypotheses are supported. Recall that our null hypothesis is that $B^{S}(v)>B^{\dot{F}}(v)>B^{A}(v)$. We do find that bids are higher in the first price auction than in the all-pay auction $\left(\tau_{2}>\tau_{1}\right)$, but we do not find that either all-pay bids or first price bids are robustly lower than second price bids (i.e., $\tau_{1}+\tau_{4}$ will always be negative and $\tau_{2}+\tau_{5}$ will remain negative for 24 or fewer expected bidders). In addition, only our all-pay bidders react as theory predicts when considering the size of the bidding population. Allpay bidders react rationally and reduce their bids as the expected number of bidders increases and the likelihood that their bids will be forfeited increases (i.e., $\tau_{3}+\tau_{4}<0$ ). At the same time, however, although second price bidders are expected to ignore the size of the bidding population, we find that they actually increase their bids when more competition is expected $\left(\tau_{3}>0\right)$ and presumably become more vulnerable to the winner's curse. Likewise, first price bidders also act contrary to theory and increase the amount that they shade their bids when more bidders are expected (i.e., $\tau_{3}+\tau_{5}<0$ ). However, the effect is economically insignificant, $\tau_{3}+\tau_{5}=-0.004$. Lastly, we do find that bids are increasing in reported private values $\left(\tau_{6}>0\right)$.

\section{Discussion}

To summarize, we find limited support for the standard models of charity auctions offered by Engers and McManus (2002) and Goeree et al. (2004) and our field results are contrary to those generated in the lab with induced altruistic preferences (e.g., Goeree and Schram, 2003). Instead of generating the most 
revenue, our all-pay auction was revenue dominated by our first price auction. Why might our field results differ from theory and the lab? We feel that the most important aspect of charity auction theory that has been neglected to this point is participation. In both theory and the lab, participation is essentially guaranteed. ${ }^{15}$ As Table 5 indicates, in the real world of fund-raising, participation is not guaranteed. Based on our casual debriefings after the auctions, the results reported in Table 5 make sense. Most participants had never heard of the all-pay auction format and only a few (those with some internet bidding experience) had experience in second price auctions. While this is bound to be true of subjects in the lab, our field participants were much more likely to respond naturally by not participating when the rules seemed too unfamiliar.

\subsection{The Revenue Cost of Non-Participation}

To get a sense of the cost imposed by the unfamiliarity of the all-pay format, in terms of reduced participation, consider the following thought experiment. Imagine that everyone who was given a bid kit participated in every auction (i.e., they bid on all 20 items). Under these circumstances, how much revenue would be generated in each of our four auctions? We can use our bid estimates generated by the sub-sample of positive bids to predict, out of sample, the bids of non-participants. Based on the bids from the entire population of attendees, we can re-evaluate the winning bids in the first price and second price auctions and sum the revenue over all the possible bids in the all-pay auctions. When we do this we find the first price auction would generate $\$ 1329.43$, the second price auction would generate $\$ 897.60$, and the two all-pay auctions would generate $\$ 3010.66$ and $\$ 4818.89$, respectively. Notice now that the order of revenues would be: all-pay (1) > all-pay (2) > first price > second price which is much closer to what section 2 predicted. Also notice that the difference between the actual revenue and our full-participation revenue is an estimate of the cost of reduced participation. The cost is negligible in the first price auction $(\$ 103.43)$ and the second price auction $(\$ 72.60)$ but it is quite substantial in the all pay auctions ( $\$ 2106.66$ and $\$ 4162.89$, respectively).

\subsection{Theoretical Foundations of Participation in Charity Auctions}

Rather than leaving the important issue of participation open, we conclude by offering a model of charity auctions that allows endogenous participation. As we will see the resulting model maps much better on to our field experimental results. We consider charity auctions with $N \geq 2$ potential risk-neutral bidders whose private values can be modelled as independent draws from some differentiable distribution function (cdf) $F$ with support $[0, \bar{v}]$. Auction revenues are used to provide some service that benefits all bidders, active or not: as in

\footnotetext{
${ }^{15}$ To be sure, lab participants may choose to bid $\$ 0$, but this sort of non-participation is almost unheard of.
} 
Goeree et al. (2004), the value of this benefit to each bidder is assumed to be a fraction $\alpha \in[0,1)$ of these revenues. At the same time, following Samuelson (1985) and Menezes and Monteiro (2000), potential bidders confront some cost of participation $c^{k} \in[0, \bar{v}), k=F($ irst $), S($ econd $), A(l l-P a y)$, the value of which is allowed to be mechanism-specific, so that the number of active bidders is not predetermined. While Samuelson [1985] and others have defined this cost in terms of the resources committed to bid preparation, we believe, on the basis of our field experiments, that a broad(er) definition, which includes cognitive difficulty of the mechanism or familiarity, is warranted. Within this framework, our derivation of the optimal symmetric rules for bidders and the calculation of expected revenues then mimics Engers and McManus (2002), with one important exception that reflects our data: we assume that there is some participation threshold $\underline{v} \geq 0$.

For the sake of brevity, the full derivation of optimal bids, expected revenues, and participation thresholds have been relocated in Appendix A. Many of our results do not depend on the particular distribution of private values that is assumed, but, as is standard in this literature, we discuss examples where the distribution is uniform.

In the first price auction with warm glow and participation costs, the risk neutral bidder who does the calculations correctly will submit the following bid:

$$
B^{F}(v)=\frac{N-1}{N-\alpha}\left(v-\frac{v^{\frac{N-\alpha}{1-\alpha}}}{v^{\frac{N-\alpha}{1-\alpha}}}\right)
$$

where $\underline{v}=\left(c^{F} \bar{v}^{N-1}\right)^{\frac{1}{N}}$ this collapses to $\frac{N-1}{N} v$ (i.e., the standard shaded bid) when bidders receive no char itable benefit $(\alpha=0)$ and there are no participation costs $(\underline{v}=0)$. The likelihood that a bidder chosen at random will submit such a bid depends on three factors: the costs of participation $c^{F}$, the maximum private value $\bar{v}$, which we interpret as a measure of the overall attractiveness of the item, and the number of potential bidders $N$. The first two do not require much comment, but the third, which has important consequences for the comparative statics of both the optimal bid and expected revenue functions, does: as the number of potential bidders increases, so, too, does the likelihood that an active bidder will forfeit her "investment" in the auction, which in turn causes the participation threshold to rise.

Given participation and bids are determined as above, expected revenue will be:

$R^{F}=\frac{N(N-1)}{(N-\alpha)(N+1)}\left(\frac{\bar{v}^{N+1}-\underline{v}^{N+1}}{\bar{v}^{N}}\right)-\frac{N(N-1)(1-\alpha)}{(N-\alpha)(1-\alpha N)} \frac{\underline{v}^{\frac{N-\alpha}{1-\alpha}}}{\bar{v}^{N}}\left(\bar{v}^{\frac{1-\alpha N}{1-\alpha}}-\underline{v}^{\frac{1-\alpha N}{1-\alpha}}\right)$

which reduces to the familiar $R^{F}=\left(\frac{N-1}{N+1}\right) \bar{v}$ when $\alpha=\underline{v}=0$.

What are the empirical implications of charitable bidding and participation costs? Figure 1(a) illustrates the variation in optimal bids as a function of private value $v$ and the number of potential bidders $N$ for the case where $\alpha=$ 
$0.20, c=0.5$ and $\bar{v}=50$. Two particular features stand out. First, despite the fact that the cost of participation is just $0.5 \%$ of mean private value (25), the non-participation zone, represented as the floor in Figure 1(b), is substantial. A potential bidder with a private value of 30 , for example, will choose not to participate when there are just 9 other bidders. Second, and perhaps a little harder to see, bids first rise and then fall as the number of potential bidders rises (as we found in section 4.3), an important qualification to the standard intuition that bidders in first price auctions cannot afford to shade their bids as much as the number of their rivals increases. Furthermore, what Figure 1 does not show is that while the existence of the "hump" in the bid function is a consequence of participation costs - it manifests itself, in other words, even when $\alpha=0$ - its location depends on the return to charitable donations: the smaller the value of $\alpha$, the smaller the critical $N$.

Along the same lines, we have plotted expected revenue $R^{F}$ as a function of the number of potential bidders $N$ and participation costs $c$ in Figure 1(b), for the same benchmark values $\alpha=0.20$ and $\bar{v}=0.50$. Given the response of individual bidders to an increase in the number of potential competitors the observation that expected revenue nevertheless rises with $N$ is an important result. In behavioral terms, the fact that there will be more high value bidders dominates the decision of more low value bidders not to participate. This is not inevitable, however: in their no spillover model, Menezes and Monteiro (2002) provide an example of a cdf of private values that cause revenues to fall.

On the other hand, participation costs do not seem to matter much, despite their pronounced effects on individual bidders. If $N=15$, expected revenues fall from 44.3 when $c=0$ to just 42.9 when $c=0.5$. However, even when participation costs are $20 \%$ of the mean private value $(c=5)$, expected revenues still exceed 36 .

Optimal bidding behavior in the second price charity auction with participation costs follows:

$$
B^{S}(v)=\frac{\alpha \bar{v}+v}{1+\alpha}
$$

One important feature of the second price bid rule stands out: neither the introduction of spillovers nor participation costs causes bidders in second price auctions to be sensitive to the number of bidders. ${ }^{16}$

Furthermore, if participation costs in first and second price auctions are the same, the participation thresholds will be, too. To see this, we note that for the threshold bidder, the difference between the expected benefits of participation and non-participation is once more $F(\underline{v})^{N-1} \underline{v}-c^{S}$, so that bidders will not be indifferent between them unless $F(\underline{v})^{N-1} \underline{v}=c^{S}$ or, in the uniform case, $\underline{v}=\left(c^{S} \bar{v}^{N-1}\right)^{\frac{1}{N}}$. In addition, the threshold is the same, mutatis mutandis, in

\footnotetext{
${ }^{16}$ Most readers will recall that without either complication, individuals will find it dominant to bid their values in second-price auctions. Menezes and Monteiro (2002) show that it remains dominant to do so in the presence of participation costs, and Engers and McManus (2002) show that the optimal bid is once more independent of $N$, so that our result comes as no surprise.
} 
the all-pay format (see below), which has the important empirical implication that controlling for differences in the number of potential bidders and attractiveness of the item as we have done in Section 5, implies that any differences in participation rates must be the result, under the maintained assumptions of our model, of differences in participation costs.

The comparative statics of $B^{S}(v)$ are more or less obvious but, for purposes of comparison, Figure 2(a) is the second price equivalent of Figure 1(a); comparing the two reveals, first and foremost, that for specified $v$ and $N$, bids in the second price auction will exceed those in the first price. Given the humpshaped response of first price bid values to increased competition, this difference first shrinks and then expands. For fixed $N$, on the other hand, the difference between them is a steadily decreasing function of private value.

The expected revenue in the second price auction is

$$
\begin{aligned}
R^{S=} & \frac{(1-\alpha)(N-1)}{(1+\alpha)}\left(\frac{\bar{v}^{N}-\underline{v}^{N}}{\bar{v}^{N-1}}\right)+\frac{\alpha N}{(1+\alpha)}\left(\frac{\bar{v}^{N-1}-\underline{v}^{N-1}}{\bar{v}^{N-2}}\right) \\
& -\frac{N(N-1)}{(1+\alpha)(N+1)}\left(\frac{\bar{v}^{N+1}-\underline{v}^{N+1}}{\bar{v}^{N}}\right)
\end{aligned}
$$

and one of the most important features of this expression is its connection to the expected revenues in a first price auction: in the absence of any spillovers (that is, $\alpha=0$ ), it is not difficult to show that the two expressions will be equal if participation costs are the same $\left(c^{S}=c^{F}\right)$. This is more or less visible in a comparison of Figure 2(b). Further comparison reveals that the second price auction produces more revenue in the absence of participation costs - that is, when participation is exogenous - than the first price, but that this difference tends to zero as $N$ tends to $\infty$. It should be added that in this case, their common limit value is $\bar{v}$, which is also the limit value when there are (also) no spillover effects: the "charity premium" is a feature, in other words, of small(er) auctions.

The optimal all-pay bidding rule is:

$$
B^{A}(v)=\frac{N-1}{N} \frac{1}{1-\alpha} \frac{v^{N}-\underline{v}^{N}}{\bar{v}^{N-1}}
$$

The characteristics of the all-pay bidding rule, as illustrated in Figures 3(a), will perhaps surprise some readers. Intuition suggests, for example, that because bidders must pay their bids, win or lose, bid values should be (much) smaller, ceteris paribus, than those in first or second price auctions. And this is indeed the case over much of the relevant domain, but as Figure 3(a) reveals, the same cannot be said about the (very) "high value bidder" faced with a substantial number of potential rivals: she will sometimes bid more than she would in either first or second price auctions. Figure 3(a) also reveals that bids in the first price and all-pay (but not second price) share an important feature: both are hump-shaped in the sense that, for specified $v$, bids first rise, and then fall, as $N$ rises. 
Aggregating up, the expected revenue under the all-pay rule is:

$$
\begin{aligned}
R^{A} & =\frac{N-1}{1-\alpha} \int_{\underline{v}(c, N)}^{\bar{v}} \frac{v^{N}-\underline{v}^{N}}{\bar{v}^{N}} d v \\
& =\frac{1}{1-\alpha} \frac{N-1}{N+1}\left(\frac{\bar{v}^{N+1}-\underline{v}^{N+1}}{\bar{v}^{N}}\right)-\frac{N-1}{1-\alpha} \frac{\underline{v}^{N}}{\bar{v}^{N}}(\bar{v}-\underline{v})
\end{aligned}
$$

As alluded to earlier, it can be shown that revenue equivalence holds if there are no spillovers $(\alpha=0)$ and participation costs are not mechanism specific. In the absence of participation costs, on the other hand, the all-pay format must (eventually) produce more revenue than either the first or second price formats: it is not difficult to show, for example, following Engers and McManus (2002), that $\lim _{N \rightarrow \infty} R^{F}=\lim _{N \rightarrow \infty} R^{S}=\bar{v}<\lim _{N \rightarrow \infty} R^{A}=\frac{1}{1-\alpha} \bar{v}$. Goeree et al (2004) provide some useful intuition for this result: bidders who top one another in first or second price auctions do not benefit from the positive externality that their all-pay counterparts do.

Some of these features are evident in Figure 3(b), drawn for the same benchmark values (in particular, $\alpha=0.20$ ) as the others: when the costs of participation are zero, for example, expected revenues exceed the limit value for first and second price auctions (that is, 50) when a tenth potential bidder is added. Indeed, inasmuch as the effects of participation costs on expected revenues seem limited, the revenue premium associated with the all-pay format appears to be robust: if $c^{A}=1$, for example, but $c^{F}$ and $c^{S}$ are held fixed at $0, R^{A}$ will still surpass 50 with the addition of a sixteenth bidder. If $c^{A}=2$, on the other hand, almost 50 potential bidders are needed.

For our current purpose, the most important feature of the model is the fact that adding mechanism-specific participation costs makes a strong prediction about differences in participation that was not obvious before solving the model. Given the maintained assumptions of the model, if participation costs are the same across formats, participation should also be the same. Of course, on the other side of this coin is the fact that participation differences can, therefore, only be caused by substantial differences in participation costs. Conveniently, our model also predicts that differences in participation costs (in the direction that seems most plausible from our experiment, $c^{A}>c^{S}>c^{F}$ ) can affect the ordering of revenues. Specifically, if we maintain $\alpha=0.2, \bar{v}=50$ etc., and set $c^{F}=0$ the model suggests we should expect, $R^{F}>R^{S}>R^{A}$ when $c^{S}$ is as low as 0.05 and $c^{A}=2.54$, which is just $5 \%$ of the highest valuation. Given our participant's reactions to the different formats, such a difference in participation costs does not seem unwarranted.

\subsection{Concluding Remarks}

With this theoretical support for our empirical results, we are more confident that our identification of endogenous participation as the source of revenue differentials in real world charity auctions is the correct one. In particular, 
charities with unsophisticated or inexperienced bidders should be reluctant to use the all-pay for mat, despite conventional wisdom, because its costs of participation are high. For such charities, the more familiar first-price format is the sensible choice.

\section{Appendix A: Derivations of the Theoretical Results on Participation}

Consider auctions with $N \geq 2$ potential risk-neutral bidders whose private values are independent draws from some differentiable distribution function (cdf) $F$ with support $[0, \bar{v}]$. All bidders benefit by a fraction $\alpha \in[0,1)$ of the total revenue earned by the charity. In addition, potential bidders face a participation cost, $c^{J} \in[0, \bar{v}), J=F($ irst $), S($ econd $), A(l l-P a y)$, which is mechanism-specific. As a result, participants only bid if their value exceeds some threshold, $\underline{v}$, and, therefore, the number of active bidders is endogenous.

\subsection{The First Price Auction}

The representative bidder in the first price auction must decide whether or not to participate and, if so, what type $\widehat{v}$ to "announce" or bid $B^{F}(\widehat{v})$ to submit. To this end, we shall first derive the conditions under which someone with the private value $v \geq \underline{v}$ finds it optimal to reveal her type when the participation threshold $\underline{v}$ is held fixed. With likelihood $C_{M}^{N-1} F(\underline{v})^{N-1-M}(1-F(\underline{v}))^{M}$, where $C_{M}^{N-1}=(N-1) ! /(N-1-M) ! M !$, she will compete with $M$ other active bidders, and conditional on $M \geq 1$, the first order statistic of her rivals' private values will have the cdf $G(x, M)=(F(x)-F(\underline{v}))^{M} /(1-F(\underline{v}))^{M}$. The conditional return on the bid $B^{F}(\widehat{v})$ is then:

$$
E U(\widehat{v}, v, M)=\int_{\underline{v}}^{\widehat{v}}\left(v-(1-\alpha) B^{F}(\widehat{v})\right) g(x, M) d x+\int_{\widehat{v}}^{\bar{v}} \alpha B^{F}(x) g(x, M) d x
$$

where $g(x, M)=d G(x, M) / d x=M(F(x)-F(\underline{v}))^{M-1} f(x) /(1-F(\underline{v}))^{M}$ is the conditional density function (pdf) of the first order statistic. The first term in (1) is her return when she wins the auction, and the second is the "charity" benefit that still accrues to her when she does not. It follows that the unconditional return $E U(\widehat{v}, v)$ will be: 


$$
\begin{aligned}
E U(\widehat{v}, v)= & F(\underline{v})^{N-1}\left(v-(1-\alpha) B^{F}(\widehat{v})\right) \\
& +\sum_{M=1}^{N-1} C_{M}^{N-1} F(\underline{v})^{N-1-M}(1-F(\underline{v}))^{M} E U(\widehat{v}, v, M) \\
= & F(\underline{v})^{N-1}\left(v-(1-\alpha) B^{F}(\widehat{v})\right) \\
& +\left(v-(1-\alpha) B^{F}(\widehat{v})\right) \sum_{M=1}^{N-1} C_{M}^{N-1} F(\underline{v})^{N-1-M}(1-F(\underline{v}))^{M} \int_{\underline{v}}^{\widehat{v}} g(x, M) d x \\
& +\alpha \sum_{M=1}^{N-1} C_{M}^{N-1} F(\underline{v})^{N-1-M}(1-F(\underline{v}))^{M} \int_{\widehat{v}}^{\bar{v}} B^{F}(x) g(x, M) d x \\
= & F(\underline{v})^{N-1}\left(v-(1-\alpha) B^{F}(\widehat{v})\right)+\left(F(\widehat{v})^{N-1}-F(\underline{v})^{N-1}\right)\left(v-(1-\alpha) B^{F}(\widehat{v})\right) \\
& +\alpha \sum_{M=1}^{N-1} C_{M}^{N-1} F(\underline{v})^{N-1-M} M \int_{\widehat{v}}^{(F(x)-F(\underline{v}))^{M-1} f(x) B^{F}(x) d x}
\end{aligned}
$$

after substitution for $G(x, M)$ and $g(x, M)$, where the first term in the first and second lines is the return in the "no other bidder" case, and the third line follows from the fact that $\int_{\underline{v}}^{\widehat{v}} g(x, M)=(F(\widehat{v})-F(\underline{v}))^{M} /(1-F(\underline{v}))^{M}$ and that, as a consequence of the binomial theorem, $\sum_{M=1}^{N-1} C_{M}^{N-1} F(\underline{v})^{N-1-M}(F(\widehat{v})-$ $F(\underline{v}))^{M}=F(\widehat{v})^{N-1}-F(\underline{v})^{N-1}$.

The derivative of $E U(\widehat{v}, v)$ with respect to the choice variable $\widehat{v}$ is therefore:

$$
\begin{aligned}
\frac{\partial E U(\widehat{v}, v)}{\partial \widehat{v}}= & -(1-\alpha) F(\widehat{v})^{N-1} \frac{d B^{F}}{d \widehat{v}} \\
& +(N-1) F(\widehat{v})^{N-2} f(\widehat{v})\left(v-(1-\alpha) B^{F}(\widehat{v})\right) \\
& -\alpha f(\widehat{v}) B^{F}(\widehat{v}) \sum_{M=1}^{N-1} C_{M}^{N-1} M F(\underline{v})^{N-1-M}(F(\widehat{v})-F(\underline{v}))^{M-1} \\
= & -(1-\alpha) F(\widehat{v})^{N-1} \frac{d B^{F}}{d \widehat{v}}+(N-1) F(\widehat{v})^{N-2} f(\widehat{v})\left(v-(1-\alpha) B^{F}(\widehat{v})\right) \\
& -\alpha(N-1) F(\widehat{v})^{N-2} f(\widehat{v}) B(\widehat{v})
\end{aligned}
$$

since, as a further consequence of the binomial theorem, $\sum_{M=1}^{N-1} C_{M}^{N-1} M F(\underline{v})^{N-1-M}(F(\widehat{v})-$ $F(\underline{v}))^{M-1}=(N-1) F(\underline{v})^{N-2}$. The relevant first order condition, $\partial E U(\widehat{v}, v) / \partial \widehat{v}=$ 0 at $\widehat{v}=v$, is therefore:

$$
\frac{d B^{F}}{d v}+\frac{N-1}{1-\alpha} \frac{f(v)}{F(v)} B^{F}(v)=(N-1) \frac{1}{1-\alpha} \frac{f(v)}{F(v)} v
$$

since $F(v) \neq 0$ for all $v \geq \underline{v}$. This differential equation is not exact, but has an integrating factor, $F(v)^{\frac{N-1}{1-\alpha}}$, so that:

$$
\frac{d\left(B^{F}(v) F(v)^{\frac{N-1}{1-\alpha}}\right)}{d v}=\frac{N-1}{1-\alpha} F(v)^{\frac{N-1}{1-\alpha}-1} f(v) v
$$

or:

$$
B^{F}(v) F(v)^{\frac{N-1}{1-\alpha}}=\frac{N-1}{1-\alpha} \int F(v)^{\frac{N-1}{1-\alpha}-1} f(v) v d v+k
$$


where $k$ is a constant of integration.

To calculate $k$, the boundary condition $B^{F}(\underline{v}) F(\underline{v})^{\frac{N-1}{1-\alpha}}=0$ is imposed, consistent with the observation that someone whose private value lies on the threshold will participate but bid 0 . It follows that:

$$
B^{F}(v) F(v)^{\frac{N-1}{1-\alpha}}=\frac{N-1}{1-\alpha} \int_{\underline{v}}^{v} F(x)^{\frac{N-1}{1-\alpha}-1} f(x) x d x+k
$$

or, after integration by parts and some simplification,

$$
B^{F}(v)=v-\frac{F(\underline{v})^{\frac{N-1}{1-\alpha}}}{F(v)^{\frac{N-1}{1-\alpha}}}-\frac{1}{F(v)^{\frac{N-1}{1-\alpha}}} \int_{\underline{v}}^{v} F(x)^{\frac{N-1}{1-\alpha}} d x
$$

For the benchmark uniform distribution $F(v)=v / \bar{v}$, the optimal bid function becomes:

$$
B^{F}(v)=\frac{N-1}{N-\alpha}\left(v-\frac{v^{\frac{N-\alpha}{1-\alpha}}}{v^{\frac{N-\alpha}{1-\alpha}}}\right)
$$

In the special case where there are neither spillovers $(\alpha=0)$ nor participation costs $\left(c^{F}=0\right.$, which implies $\left.\underline{v}=0\right)$, the bid function collapses to the familiar $B^{F}(v)=\frac{N-1}{N} v$, in which bids are "shaded" $1 / N$ below private values. If spillovers (alone) are reintroduced, it becomes $B^{F}(v)=\frac{N-1}{N-\alpha} v$, consistent with Engelbrecht-Wiggans (1994), who first showed that $B^{F}(v)=\frac{1}{2-\alpha} v$ when there are two bidders, and Goeree et al. (2004). Without spillovers but with participation costs, it reduces to:

$$
B^{F}(v)=\frac{N-1}{N}\left(\frac{v^{N}-\underline{v}^{N}}{v^{N-1}}\right)
$$

which is equivalent to Menezes and Monteiro's (2002) result for first price auctions. $^{17}$

Inasmuch as the participation threshold $\underline{v}$ is endogenous to the model, however, the optimal bid function (7) is not a reduced form in the usual sense. To remedy this, we observe that (a) an individual with the threshold private value should be indifferent between participation (and a zero bid) and nonparticipation and (b) the positive spillovers that (sometimes) result from the decisions of other bidders are not conditional on participation. It follows from (2), therefore, that $\underline{v}$ must solve:

\footnotetext{
${ }^{17} \mathrm{On}$ the basis of their somewhat different approach, Menezes and Monteiro (2002) show that, in terms of our notation:$$
B^{F}(v)=\frac{\int_{\underline{v}}^{v}(N-1) x F(x)^{N-2} f(x) d x}{F(v)^{N-1}}
$$

which simplifies to our (9) when the distribution of values is uniform.
} 


$$
\underline{v} F(\underline{v})^{N-1}=c^{F}
$$

Given (b), it comes as no surprise that this threshold is the same as that derived in Menezes and Monteiro (2002) in the "no spillover case." For a uniform distribution of private values, (10) implies that $\underline{v}=\left(c^{F} \bar{v}^{N-1}\right)^{\frac{1}{N}}$.

Charities will be less interested in bid values, however, than expected revenues $R^{F}$. To calculate $R^{F}$, we first note that if the first order statistic for all $N$ potential bidders, $x$, is below $\underline{v}$, no one bids and revenues are zero, but that if it exceeds $\underline{v}$, revenues will be $B^{F}(x)$. Since the pdf for the first order statistic is $N F(x)^{N-1} f(x)$ in the general case, it follows that:

$$
R^{F}=N \int_{\underline{v}(c, N)}^{\bar{v}} F(x)^{N-1} f(x) B^{F}(x) d v
$$

where the threshold value is written $\underline{v}(c, N)$ as a reminder that the lower limit is not fixed in the usual sense. In the uniform case, this can be written:

$$
R^{F}=\frac{N(N-1)}{(N-\alpha) \bar{v}^{N}} \int_{\underline{v}(c, N)}^{\bar{v}} x^{N+1} d x-\frac{N(N-1)}{(N-\alpha)} \frac{\underline{v}^{\frac{N-\alpha}{1-\alpha}}}{\bar{v}^{N}} \int_{\underline{v}(c, N)}^{\bar{v}} x^{\frac{1-\alpha N}{1-\alpha}} d x
$$

or, after integration and some simplification:

$R^{F}=\frac{N(N-1)}{(N-\alpha)(N+1)}\left(\frac{\bar{v}^{N+1}-\underline{v}^{N+1}}{\bar{v}^{N}}\right)-\frac{N(N-1)(1-\alpha)}{(N-\alpha)(1-\alpha N)} \frac{\underline{v}^{\frac{N-\alpha}{1-\alpha}}}{\bar{v}^{N}}\left(\bar{v}^{\frac{1-\alpha N}{1-\alpha}}-\underline{v}^{\frac{1-\alpha N}{1-\alpha}}\right)$

where $\underline{v}=\left(c^{F} \bar{v}^{N-1}\right)^{\frac{1}{N}}$. In the absence of either spillovers or participation costs, $R^{F}=\left(\frac{N-1}{N+1}\right) \bar{v}$, a familiar result. With spillovers, but without participation costs, expected revenues become $R^{F}=\left(\frac{N(N-1)}{(N-\alpha)(N+1)}\right) \bar{v}$, consistent with Engers and McManus (2002). It should be noted that when bidders receive such benefits, revenues increase but that the difference vanishes as the number of bidders rises: both expressions tend to $\bar{v}$ as $N$ tends to $\infty$. With participation costs but without spillovers, on the other hand, expected revenues are:

$$
R^{F}=\frac{(N-1)}{(N+1)}\left(\frac{\bar{v}^{N+1}-\underline{v}^{N+1}}{\bar{v}^{N}}\right)-(N-1)\left(\frac{\underline{v}}{\bar{v}}\right)^{N}(\bar{v}-\underline{v})
$$

\subsection{The Second-Price Auction}

The derivation of the optimal bid and expected revenue functions in the second price auction requires the introduction of another cdf $J(x, M)$, the conditional distribution of the second order statistic when there are $M$ other active bidders:

$$
J(x, M)=M\left(\frac{F(x)-F(\underline{v})}{1-F(\underline{v})}\right)^{M-1}-(M-1)\left(\frac{F(x)-F(\underline{v})}{1-F(\underline{v})}\right)^{M}
$$


as well as the (related) likelihood that a bidder who "announces" type $\widehat{v}$ is the runner-up, since the winner then pays $B^{S}(\widehat{v})$ :

$M\left(\frac{F(\widehat{v})-F(\underline{v})}{1-F(\underline{v})}\right)^{M-1}\left(1-\frac{F(\widehat{v})-F(\underline{v})}{1-F(\underline{v})}\right)=\frac{M(F(\widehat{v})-F(\underline{v}))^{M-1}(1-F(\widehat{v}))}{(1-F(\underline{v}))^{M}}$

Given these preliminaries, we then observe that with likelihood $F(\underline{v})^{N-1}$, the representative bidder will have no active competitors - the "second price" is then assumed to be zero - in which case she will receive $v$ no matter what bid $B^{S}(\widehat{v})$ she has submitted. As a result, the optimal threshold bid is indeterminate, which in turn complicates the choice of boundary condition, as discussed below. With likelihood $C_{M}^{N-1} F(\underline{v})^{N-1-M}(1-F(\underline{v}))^{M}$, on the other hand, there will be $M \geq 1$ other active bidders, in which case:

$$
\begin{aligned}
E U(\widehat{v}, v, M)= & \int_{\underline{v}}^{\widehat{v}}\left(v-(1-\alpha) B^{S}(x)\right) g(x, M) d x \\
& +\frac{M(F(\widehat{v})-F(\underline{v}))^{M-1}(1-F(\widehat{v}))}{(1-F(\underline{v}))^{M}} \alpha B^{S}(\widehat{v}) \\
& +\alpha \int_{\widehat{v}}^{\bar{v}} B^{S}(x) j(x, M) d x
\end{aligned}
$$

where:

$$
j(x, M)=\frac{d J(x, M)}{d x}=\frac{M(M-1)(F(x)-F(\underline{v}))^{M-2}(1-F(x)) f(x)}{(1-F(\underline{v}))^{M}}
$$

is the pdf of the second order statistic. The first term is once more the benefit that accrues to her when she wins - the difference between (1) and (18) is the bid is now $B^{S}(x)$ rather than $B^{F}(\widehat{v})$ - and the third captures the direct spillover effect when she does not. The second is the indirect effect of her bid on the winner's payment when she is the runner-up.

It follows, therefore, that the unconditional return will be:

$$
\begin{aligned}
E U(v, \widehat{v})= & F(\underline{v})^{N-1} v+\left(\sum_{M=1}^{N-1} C_{M}^{N-1} F(\underline{v})^{N-1-M} M\right) \times \\
& \left(\int_{\underline{v}}^{\widehat{v}}\left(v-(1-\alpha) B^{S}(x)\right)\left(F(x)-F(\underline{v})^{M-1} f(x) d x\right)\right. \\
& +\alpha(1-F(\widehat{v})) B^{S}(\widehat{v}) \sum_{M=1}^{N-1} C_{M}^{N-1} M F(\underline{v})^{N-1-M}(F(\widehat{v})-F(\underline{v}))^{M-1} \\
& +\left(\alpha \sum_{M=1}^{N-1} C_{M}^{N-1} M(M-1) F(\underline{v})^{N-1-M}\right) \times \\
& \left(\int_{\widehat{v}}^{\bar{v}} B^{S}(x)(F(x)-F(\underline{v}))^{M-2}(1-F(x)) f(x) d x\right)
\end{aligned}
$$


Because the partial derivatives of the third and fourth terms with respect to $\widehat{v}$ both contain the term $\alpha(1-F(\widehat{v})) B^{S}(\widehat{v}) \sum_{M=1}^{N-1} C_{M}^{N-1} M(M-1) F(\underline{v})^{N-1-M}(F(\widehat{v})-$ $F(\underline{v}))^{M-2} f(\widehat{v})$, the expression for $\partial E U(v, \widehat{v}) / \partial \widehat{v}$ collapses to:

$$
\begin{aligned}
\frac{\partial E U(v, \widehat{v})}{\partial \widehat{v}}= & (N-1)\left(v-(1-\alpha) B^{S}(\widehat{v})\right) F(\widehat{v})^{N-2} f(\widehat{v}) \\
& +\alpha\left((1-F(\widehat{v})) \frac{d B^{S}}{d \widehat{v}}-f(\widehat{v}) B^{S}(\widehat{v})\right) \times \\
& \sum_{M=1}^{N-1} C_{M}^{N-1} M F(\underline{v})^{N-1-M}(F(\widehat{v})-F(\underline{v}))^{M-1} \\
= & (N-1)\left(v-(1-\alpha) B^{S}(\widehat{v})\right) F(\widehat{v})^{N-2} f(\widehat{v}) \\
& +\alpha(N-1)\left[(1-F(\widehat{v})) \frac{d B^{S}}{d \widehat{v}}-f(\widehat{v}) B^{S}(\widehat{v})\right] F(\widehat{v})^{N-2}
\end{aligned}
$$

Setting $\partial E U(v, \widehat{v}) / \partial \widehat{v}=0$ at $v=\widehat{v}$ and dividing both sides by $(N-1) F(\widehat{v})^{N-2} \neq$ 0 then leads to the first order condition:

$$
\alpha(1-F(v)) \frac{d B^{S}}{d v}-f(v) B^{S}(v)=-v f(v)
$$

or, if $v \neq \bar{v}$ and $\alpha=0^{18}$ :

$$
\frac{d B^{S}}{d v}-\frac{f(v)}{\alpha(1-F(v))} B^{S}(v)=-\frac{v f(v)}{\alpha(1-F(v))}
$$

Multiplying both sides by the integrating factor $(1-F(v))^{\frac{1}{\alpha}}$ produces:

$$
\frac{d\left((1-F(v))^{\frac{1}{\alpha}} B^{S}(v)\right)}{d v}=-\frac{v f(v)(1-F(v))^{\frac{1-\alpha}{\alpha}}}{\alpha}
$$

or:

$$
(1-F(v))^{\frac{1}{\alpha}} B^{S}(v)=-\frac{1}{\alpha} \int v f(v)(1-F(v))^{\frac{1-\alpha}{\alpha}}+k
$$

where $k$ is the constant of integration.

The choice of boundary condition, and therefore the calculation of $k$, is complicated for two reasons. The optimal threshold bid $B^{S}(\underline{v})$ is, as noted above, indeterminate, but the derivation of (23) assumed that $v \neq \bar{v}$. The second problem can be circumvented, however, if the the domain of $(1-F(v))^{\frac{1}{\alpha}} B^{S}(v)$ is (re)extended to $\bar{v}$ such that $(1-F(\bar{v}))^{\frac{1}{\alpha}} B^{S}(\bar{v})$ assumes its limit value of 0 . It then follows that:

$$
(1-F(v))^{\frac{1}{\alpha}} B^{S}(v)=\frac{1}{\alpha} \int_{v}^{\bar{v}} x f(x)(1-F(x))^{\frac{1-\alpha}{\alpha}} d x
$$

Integration by parts then implies:

\footnotetext{
${ }^{18}$ If $\alpha=\mathbf{0}$, then (23) collapses to $B S(v)=v$, and no further manipulation is needed.
} 


$$
(1-F(v))^{\frac{1}{\alpha}} B^{S}(v)=(1-F(v))^{\frac{1}{\alpha}} v+\int_{v}^{\bar{v}}(1-F(x))^{\frac{1}{\alpha}} d x
$$

or, if one once more requires that $v \neq \bar{v}$ :

$$
B^{S}(v)=v+\frac{1}{(1-F(v))^{\frac{1}{\alpha}}} \int_{v}^{\bar{v}}(1-F(x))^{\frac{1}{\alpha}} d x
$$

where the limit bids $B^{S}(\underline{v})$ and $B^{S}(\bar{v})$ are chosen so that $B^{S}(v)$ is continuous over $[\underline{v}, \bar{v}]$.

When the distribution of private values is uniform, the optimal second-price bid is a simple linear function of private value:

$$
B^{S}(v)=\frac{\alpha \bar{v}+v}{1+\alpha}
$$

Except for the domain restriction - individuals with private values below the threshold do not bid at all - this is the same function obtained in Goeree et al (2004) and Engers and McManus (2002).

It is the second order statistic of private values, with unconditional pdf $N(N-1) F(x)^{N-2}(1-F(x)) f(x)$, that drives expected revenues $R^{S}$ :

$$
R^{S}=\int_{\underline{v}\left(c^{S}, N\right)}^{\bar{v}} N(N-1) F(x)^{N-2}(1-F(x)) f(x) B^{S}(x) d x
$$

In the uniform case, this becomes:

$R^{S}=\frac{N(N-1)}{\bar{v}^{N}} \int_{\underline{v}\left(c^{S}, N\right)}^{\bar{v}} x^{N-1}(\bar{v}-x) d x+\frac{N(N-1) \alpha}{(1+\alpha) \bar{v}^{N}} \int_{\underline{v}\left(c^{S}, N\right)}^{\bar{v}} x^{N-2}(\bar{v}-x)^{2} d x$

where the separation of terms allows the spillover effect to be isolated. Evaluation of the integrals and collection of term then produces:

$$
\begin{aligned}
R^{S=} & \frac{(1-\alpha)(N-1)}{(1+\alpha)}\left(\frac{\bar{v}^{N}-\underline{v}^{N}}{\bar{v}^{N-1}}\right)+\frac{\alpha N}{(1+\alpha)}\left(\frac{\bar{v}^{N-1}-\underline{v}^{N-1}}{\bar{v}^{N-2}}\right) \\
& -\frac{N(N-1)}{(1+\alpha)(N+1)}\left(\frac{\bar{v}^{N+1}-\underline{v}^{N+1}}{\bar{v}^{N}}\right)
\end{aligned}
$$

where, of course, $\underline{v}=\left(c^{S} \bar{v}^{N-1}\right)^{\frac{1}{N}}$.

\subsection{The All-Pay Auction}

The derivation of the optimal bid under the all-pay mechanism follows now familiar lines. With probability $F(\underline{v})^{N-1}$, the representative bidder will have no other rivals, and can expect $(v-(1-\alpha) B(\widehat{v}))$. With probability $C_{M}^{N-1} F(\underline{v})^{N-1-M}(1-$ $F(\underline{v}))^{M}$, however, there will be $M \geq 1$ other bidders, with conditional payoff: 


$$
E U(\hat{v}, v, M)=\int_{\underline{v}}^{\widehat{v}} v g(x, M) d x+\frac{\alpha M}{(1-F(\underline{v}))} \int_{\underline{v}}^{\bar{v}} f(x) B^{A}(x) d x-(1-\alpha) B^{A}(\widehat{v})
$$

The first term term reflects the fact that the bidder receives her private value $v$ if she wins the auction, while the second and third follow from the observation that, win or lose, she loses the (net) cost of her bid $(1-\alpha) B^{A}(\widehat{v})$ but receives a benefit equal to a fraction of $\alpha$ of the sum of the other bids, expressed here as a fraction of the product of the number of active bidders $M$ and the conditional mean bid, $M \int_{\underline{v}}^{\bar{v}} \frac{f(x)}{1-F(\underline{v})} B^{A}(x) d x$. The unconditional payoff $E U(v, \hat{v})$ will therefore be:

$$
\begin{aligned}
E U(v, \hat{v})= & F(\underline{v})^{N-1}\left(v-(1-\alpha) B^{A}(\widehat{v})\right) \\
& +\sum_{M=1}^{N-1} C_{M}^{N-1} F(\underline{v})^{N-1-M}(1-F(\underline{v}))^{M} \int_{\underline{v}}^{\widehat{v}} v g(x, M) d x \\
& +\sum_{M=1}^{N-1} C_{M}^{N-1} F(\underline{v})^{N-1-M}(1-F(\underline{v}))^{M} \int_{\underline{v}}^{\widehat{v}} v g(x, M) d x \\
& +\frac{\alpha}{(1-F(\underline{v}))} \int_{\underline{v}}^{\bar{v}} B^{A}(x) f(x) d x \sum_{M=1}^{N-1} C_{M}^{N-1} M F(\underline{v})^{N-1-M}(1-F(\underline{v}))^{M} \\
& +(1-\alpha) B^{A}(\widehat{v}) \sum_{M=1}^{N-1} C_{M}^{N-1} F(\underline{v})^{N-1-M}(1-F(\underline{v}))^{M}
\end{aligned}
$$

Recalling that $g(x, M)=M(F(x)-F(\underline{v}))^{M-1} f(x) /(1-F(\underline{v}))^{M}$ and observing that $v \int_{\underline{v}}^{\widehat{v}} M(F(x)-F(\underline{v}))^{M-1} f(x) d x=v(F(\widehat{v})-F(\underline{v}))^{M}$, the second term becomes, after application of the binomial theorem, $v\left(F(\widehat{v})^{N-1}-F(\underline{v})^{N-1}\right)$. For similar reasons, the third and fourth terms collapse to $\alpha(N-1) \int_{\underline{v}}^{\bar{v}} B^{A}(x) f(x) d x$, and the fourth, to $(1-\alpha)(1-F(\underline{v}))^{N-1} B^{A}(\widehat{v})$, respectively, so that, collecting terms, we have:

$$
E U(v, \hat{v})=v F(\widehat{v})^{N-1}-(1-\alpha) B^{A}(\widehat{v})+\alpha(N-1) \int_{\underline{v}}^{\bar{v}} B^{A}(x) f(x) d x
$$

The partial derivative of $E U(v, \hat{v})$ with respect to $\hat{v}$ is therefore $v(N-$ 1) $F(\widehat{v})^{N-2} f(\widehat{v})-(1-\alpha) \frac{d B^{A}(\widehat{v})}{d \hat{v}}$ and the requirement that this derivative be equal to zero at $\hat{v}=v$ implies that:

$$
\frac{d B^{A}(v)}{d v}=\frac{N-1}{1-\alpha} v F(v)^{N-2} f(v)
$$

so that:

$$
B^{A}(v)=\frac{N-1}{1-\alpha} \int v F(v)^{N-2} f(v) d v+k
$$

With the constant of integration $k$ chosen so that $B^{A}(\underline{v})=0$, the optimal bid function is then: 


$$
B^{A}(v)=\frac{N-1}{1-\alpha} \int_{\underline{v}(c, N)}^{v} x F(x)^{N-2} f(x) d x
$$

which reduces to the bid functions in Goeree et al. (2004) and Engers and McManus (2002) in the special case where $c=\underline{v}=0$. For a uniform distribution of private values, the bid function becomes:

$$
B^{A}(v)=\frac{N-1}{N} \frac{1}{1-\alpha} \frac{v^{N}-\underline{v}^{N}}{\bar{v}^{N-1}}
$$

where, for the same rationale described in the sections on first and second price auctions, $\underline{v} F(\underline{v})^{N-1}=c^{A}$ or $\underline{v}=\left(c^{A} \bar{v}^{N-1}\right)^{\frac{1}{N}}$.

To calculate expected revenue, we observe that the expected bid for someone chosen at random from the pool of potential participants is $\int_{\underline{v}}^{\bar{v}} B^{A}(v) f(v) d v$ since she does not bid when her private value is less than $\underline{v}(c, N)$ but with "likelihood" $f(v)$, she bids $B^{A}(v)$ otherwise. With $N$ such bidders, each of whom now "forfeits" her bid, it follows that:

$$
R^{A}=N \int_{\underline{v}(c, N)}^{\bar{v}} B^{A}(v) f(v) d v
$$

or, in the uniform case:

$$
\begin{aligned}
R^{A} & =\frac{N-1}{1-\alpha} \int_{\underline{v}(c, N)}^{\bar{v}} \frac{v^{N}-\underline{v}^{N}}{\bar{v}^{N}} d v \\
& =\frac{1}{1-\alpha} \frac{N-1}{N+1}\left(\frac{\bar{v}^{N+1}-\underline{v}^{N+1}}{\bar{v}^{N}}\right)-\frac{N-1}{1-\alpha} \underline{v}^{N} \bar{v}^{N}(\bar{v}-\underline{v})
\end{aligned}
$$

where $\underline{v}=\left(c^{A} \bar{v}^{N-1}\right)^{\frac{1}{N}}$.

\section{Appendix B: Experimental Instructions and Our Survey}

\section{Instructions}

This is a sealed bid auction. You will receive no information about the bids of the other participants and they will receive no information about your bids. [First Price: The person who places the highest bid will receive the item and, in turn, make a contribution to this day care center for the amount of the bid.] [Second Price: The person who places the highest bid will receive the item and, in turn, make a contribution to this day care center for the amount of the second highest bid. That is, the highest bidder wins but only has to pay the second highest bid.] [All-pay: The person who places the highest bid will receive the item. However, this is an All-pay Auction which means that everyone must pay their bids whether or not they are the highest bidder.] Bids will be accepted until $6: 30 \mathrm{pm}$ and we will announce the winning bids at 7:00pm. [First and 
Second Price: If you make the highest bid on an item, you must pay with cash or write out a check to this day care center.] [All-pay: You must pay for each bid with cash or a check made out to this preschool.] If you have to leave before 7:00pm, place bids on items and we will call you only if you make the winning bid on an item. Please remember that all bids will go directly and entirely to this preschool. You may direct any questions about the items being auctioned off or the procedures of the auction to one of the auctioneers.

Bid Kit Sample

Bidder Number:

Panasonic DVD Player (retail value: $\$ 100$ )

Would you buy this item in a store? Yes No

If Yes, what is the most you would pay for this item in a store? $\$_{-}-$

How much would you bid in a similar auction not conducted for charity? \$__

Sex of bidder: Male Female Joint Decision

Your Bid for this item $\${ }_{-}$(there is no minimum bid)

Survey

Please fill in the following information about the adult members of your family.

\begin{tabular}{|l|l|l|l|l|l|l|l|l|l}
\hline & \multirow{2}{*}{ Sex } & Age & Marital & \multicolumn{5}{|c|}{ Schooling: Please check one box } & \multirow{2}{*}{ Occupation } \\
\cline { 4 - 7 } & & & Status & $\begin{array}{c}\text { Less than } \\
\text { High } \\
\text { School }\end{array}$ & $\begin{array}{c}\text { High } \\
\text { School } \\
\text { degree }\end{array}$ & $\begin{array}{c}\text { Some } \\
\text { College }\end{array}$ & $\begin{array}{c}\text { College } \\
\text { degree }\end{array}$ & $\begin{array}{c}\text { Advanced } \\
\text { degree }\end{array}$ & \\
\hline Adult 1 & & & & & & & & & \\
\hline Adult 2 & & & & & & & & & \\
\hline Adult 3 & & & & & & & & & \\
\hline Adult 4 & & & & & & & & & \\
\hline
\end{tabular}

Please fill in the following information about the children in your family. We are interested in how much contact your family has had, and will have, with this preschool center. 


\begin{tabular}{|l|l|l|}
\hline & $\begin{array}{c}\text { How many years has (or did) } \\
\text { child attend this preschool? }\end{array}$ & $\begin{array}{c}\text { How many more years will child } \\
\text { attend this preschool (include infants } \\
\text { not yet enrolled)? }\end{array}$ \\
\hline Child 1 & & \\
\hline Child 2 & & \\
\hline Child 3 & & \\
\hline Child 4 & & \\
\hline Child 5 & & \\
\hline Child 6 & & \\
\hline
\end{tabular}

Is your family happy with the service provided by this preschool (please circle one)?

Very Unhappy $12345 \quad$ Very Happy

Is anyone in your family currently on the advisory board of this preschool? Yes No No

Has anyone in your family been on the advisory board of this preschool? Yes

Is anyone in your family currently employed by this preschool? Yes No

Estimate how much your family has already donated to this preschool since January 1, 2003 (not including any donations in the auction). \$

Estimate how many total hours of service your family has donated to this preschool since January 1, 2003? total hours

Town of residence:

$\square$ Addison $\square$ Bridport $\square$ Bristol $\mathbf{\square}$ Cornwall $\mathbf{\square}$ Ferrisburgh $\mathbf{\square}$ Goshen Granville Leicester $\square$ Lincoln $\square$ Middlebury Monkton $\square$ New Haven Orwell $\square$ Panton $\square$ Ripton $\square$ Salisbury $\square$ Shoreham $\square$ Starksboro $\square$ Sudbury $\square$ Vergennes $\square$ Waltham $\square$ Weybridge $\square$ Whiting

How long has your family lived in this area: years.

Annual Household Income (please circle one):
(a) $\$ 0-\$ 25,000$
(b) $\$ 25,001-\$ 50,000$
(c) $\$ 50,001-\$ 75,000$
(d) $\$ 75,001-\$ 100,000$
(e) $\$ 100,001-\$ 125,000$ 
(f) $\$ 125,001-\$ 150,000$

(g) $\$ 150,001-\$ 175,000$

(h) more than $\$ 175,000$

Estimated annual charitable giving: $\$$

Do you have any past experience participating in charity auctions? Yes No No

Do you have any past experience participating in non-charity auctions? Yes

Your Phone Number (we will only use this if you need to leave before the end of the auction and you win an item):

\section{Appendix C: Selection Models of Participa- tion and Bidding}

The close relationship between auction participation and bid value suggests that bidders may not be a random sample of all auction attendees; researchers must be aware of the potential for sample selection bias when estimating the determinants of bid value.

To better understand how selection bias can affect the analysis of bid behavior, begin by letting $P_{i, j}^{*}$ be a latent random variable for bidder $i$ which is some measure of the individual's desire to bid in auction $j$. Assume that $P_{i, j}^{*}$ is a linear function of a set of non-stochastic independent variables and an error term. These covariates include information on the auction mechanism $\left(A_{j}\right)$; vectors of demographic $\left(D_{i, j}\right)$ information; individual $i^{\prime} s$ estimate of the total number of bidders on item $j\left(N_{i, j}\right)$; the retail price of item $j$ and its square $\left(R_{i, j}\right)$ and a set of interactions designed to test whether the effect on bid value of expected bidders differs by auction type $\left(A_{j} \times N_{i, j}\right)$. The participation process can then be estimated as follows:

$$
P_{i, j}^{*}=t_{0}+t_{1} A_{j}+t_{2} D_{i, j}+t_{3} N_{i, j}+t_{4} R_{i, j}+t_{5}\left(A_{j} \times N_{i, j}\right)+t_{6} v_{i, j}+t_{7} \alpha_{i}+\epsilon_{i, j}
$$

where $\epsilon_{i, j}$ is iid $\sim N(0,1)$.

In fact, $P_{i, j}^{*}$, a measure of the individual's willingness to bid on the item, is not observed; only the sign of $P_{i, j}^{*}$ is known. If an individual submits a bid, then $P_{i, j}^{*}$ is assumed to be positive and $P_{i, j}$ takes the value of 1 . If an individual does not submit a bid, then $P_{i, j}^{*}$ is assumed to be negative and we observe $P_{i, j}$ $=0$.

Let $B_{i, j}$ be the bid on item $j$ submitted for individual $i$ (observed only when $P_{i, j}=1$ ). Assume that $B_{i, j}$ is also a linear function of a set of nonstochastic independent variables and an error term. These covariates again include auction mechanism $\left(A_{j}\right)$, demographic information $\left(D_{i, j}\right)$, expectations regarding the number of other bidders $\left(N_{i, j}\right)$, retail price and its square $\left(R_{i, j}\right)$ and the same set of interactions as above $\left(A_{j} \times N_{i, j}\right)$. The bid function can thus be estimated as follows: 
$(C .2) \quad B_{i, j}=g_{0}+g_{1} A_{j}+g_{2} D_{i, j}+g_{3} N_{i, j}+g_{4} R_{i, j}+g_{5}\left(A_{j} \times N_{i, j}\right)+n_{i, j}$

where $n_{i, j}$ is iid $\sim N(0,1)$.

Sample selection bias arises if there exists some correlation among the errors, $\epsilon_{i, j}$ and $n_{i, j}$ in equations (A.1) and (A.2). For example, if we assume that $\left(\epsilon_{i, j}, n_{i, j}\right)$ bivariate normal $\left(0,0,1, \sigma_{\epsilon}, \rho\right)$ then $\rho$ is a measure of the correlation among the errors. The correlation between the two errors will be positive, if the unobserved determinant increases both the probability of participation and bid value. Furthermore, the conditional mean bid will be higher than the unconditional mean bid if $\rho$ is positive, and lower if $\rho$ is negative. If correction is not made, then the estimates of the coefficients in equation (A.2) will be biased and inconsistent.

The Heckman selection model (Heckman, 1979) is the appropriate empirical tool in this situation; it corrects for the fact that the sample of individuals who submit bids may be systematically different from those who do not and allow us to use information from non-bidders to obtain consistent parameter estimates of the determinants of bid value. In order to identify the selection equation, we use an indicator for 'employee or board member' (rather than relying on functional form assumptions). Employees and board members (i.e., event organizers) are likely to face external pressure to participate in the auction since participation is publicly observed. However, since bids are sealed, employee or board member status should have no additional impact on bids confidentially submitted.

Table C reports the Heckman results. Model (1), the basic specification, includes information on auction-type, expected number of bidders, retail value, and demographic characteristics of bidders. Model (2) adds interactions between auction-type and expected number of bidders. The most extensive specification, Model (3), includes all covariates in Models (1) and (2) but adds information on reported private values. The first two models suggest that selection matters (i.e., the inverse Mill's ratios are weakly significant); bid functions estimated only on participants are subject to sample selection bias. However, once we include reported private values (Model (3)), the inverse Mill's ratio becomes insignificant and $\rho$ falls from .42 to .09 . The key implication is that if private values are known (or induced in the lab), the Heckman selection model is no longer necessary and auction participation and bid behavior can be estimated independently. However, field experiments that fail to survey individuals about private values are susceptible to selection bias in their bid estimates.

\section{References}

Andreoni, J., 1989. Giving with impure altruism: Applications to charity and Ricardian equivalence. Journal of Political Economy. 97, 1447-1458.

Carpenter, J., Harrison, G., List, J., 2004. Field experiments in economics: An introduction. In: Carpenter, J., Harrison, G., List, J. (Eds.), Field experiments in economics, JAI/Elsevier, Greenwich, Conn, and London, pp. 
Davis, D., Razzolini, L., Reilly, R., Wilson, B., 2003. Raising revenues for charity: Auctions versus lotteries. Department of Economics, University of Mississippi Working Paper.

Engelbrecht-Wiggans, R., 1994. Auctions with price-proportional benefits to bidders. Games and Economic Behavior. 6, 339-346.

Engers, M., McManus, B., 2002. Charity auctions. Department of Economics, University of Virginia Working Paper.

Fibich, G., Gavious, A., Sela, A., 2002. All-pay auctions with risk averse buyers. Department of Economics, Ben-Gurion University Working Paper.

Goeree, J.K., Maasland, E., Onderstal, S., Turner, J., 2004. How (not) to raise money. Department of Economics, University of Virginia Working Paper.

Goeree, J.K., Schram, A., 2003. Bidding to give: An experimental comparison of auctions for charity. CREED, University of Amsterdam, Working Paper.

Heckman, J., 1979. Sample selection bias as a specification error. Econometrica. 47, 153-161.

Isaac, R.M., Schneir, K., 2003. Run silent, run cheap? A study of a charity auction mechanism. Department of Economics, Florida State University Working Paper.

Jehiel, P., Moldovanu, B., Stacchetti, E., 1996. How (not) to sell nuclear weapons. American Economic Review. 86, 814-829.

Kagel, J.H., 1995. Auctions: A survey of experimental research. In: Kagel, J. H., Roth, A. E. (Eds.), The handbook of experimental economics, Princeton University Press, Princeton, pp. 501-585.

Klemperer, P., 1999. Auction theory: A guide to the literature. Journal of Economic Surveys. 13, 227-286.

Krishna, V., 2002. Auction theory. Academic Press, New York.

Laffont, J.-J., 1997. Game theory and empirical economics: The case of auction data. European Economic Review. 41, 1-35.

List, J.A., Lucking-Reiley, D., 2000. Demand reduction in multiunit auctions: Evidence from a sportscard field experiment. American Economic Review. 90, 961-972.

Lucking-Reiley, D., 1999. Using field experiments to test equivalence between auction formats: Magic on the internet. American Economic Review. 89, 1063-1080.

Maskin, E.S., Riley, J.G., 1984. Optimal auctions with risk averse buyers. Econometrica. 52, 1473-1518.

Menezes, F.M., Monteiro, P.K., 2000. Auctions with endogenous participation. Review of Economic Design. 5, 71-89.

Morgan, J., Sefton, M., 2000. Funding public goods with lotteries: Experimental evidence. Review of Economic Studies. 67, 785-810.

Orzen, H., 2003. Fundraising through competition: Theory and experiments. Presentation at the 2003 ESA European Conference.

Samuelson, W., 1985. Competitive bidding with entry costs. Economics Letters. $17,53-57$. 
Stegeman, Mark (1996) Participation costs and efficient auctions. Journal of Economic Theory 71: 228-259.

Vickrey, W., 1961. Counterspeculation, auctions, and competitive sealed bid tenders. Journal of Finance. 16, 8-37.

\section{Tables and Figures}

\begin{tabular}{|c|c|c|c|c|c|c|}
\hline & & & First Price & Second Price & All-Pay(1) & All-Pay(2) \\
\hline Item & Type & Retail Value & Revenue & Revenue & Revenue & Revenue \\
\hline Deli & Gift Certificate & $\$ 10$ & $\$ 15$ & $\$ 10$ & $\$ 0$ & $\$ 11$ \\
\hline Children's Science Book & Book & $\$ 13$ & $\$ 15$ & $\$ 15$ & $\$ 1$ & $\$ 0$ \\
\hline Bakery & Tart & $\$ 15$ & $\$ 16$ & $\$ 20$ & $\$ 62$ & $\$ 27$ \\
\hline Chocolate Making Kit & Craft & $\$ 15$ & $\$ 15$ & $\$ 10$ & $\$ 0$ & $\$ 1$ \\
\hline Craft/Toy Store & Gift Certificate & $\$ 20$ & $\$ 35$ & $\$ 25$ & $\$ 20$ & $\$ 5$ \\
\hline Cadoo Cranium & Game & $\$ 20$ & $\$ 20$ & $\$ 15$ & $\$ 10$ & $\$ 6$ \\
\hline Sports/Clothing Store & Gift Certificate & $\$ 25$ & $\$ 30$ & $\$ 30$ & $\$ 52$ & $\$ 13$ \\
\hline Pizzeria & Gift Certificate & $\$ 30$ & $\$ 50$ & $\$ 20$ & $\$ 5$ & $\$ 0$ \\
\hline Kitchen Store & Gift Certificate & $\$ 40$ & $\$ 40$ & $\$ 50$ & $\$ 110$ & $\$ 13$ \\
\hline Garden Item & Spruce Tree & $\$ 40$ & $\$ 30$ & $\$ 45$ & $\$ 25$ & $\$ 0$ \\
\hline Pewter Item & Picture Frame & $\$ 42$ & $\$ 25$ & $\$ 45$ & $\$ 30$ & $\$ 19$ \\
\hline Restaurant (a) & Gift Certificate & $\$ 50$ & $\$ 75$ & $\$ 65$ & $\$ 104$ & $\$ 58$ \\
\hline Wooden Train Tracks & Toy & $\$ 50$ & $\$ 30$ & $\$ 75$ & $\$ 0$ & $\$ 46$ \\
\hline Performing Arts & Tickets & $\$ 60$ & $\$ 75$ & $\$ 75$ & $\$ 55$ & $\$ 25$ \\
\hline Auto Detailing & Gift Certificate & $\$ 75$ & $\$ 100$ & $\$ 100$ & $\$ 32$ & $\$ 26$ \\
\hline Restaurant (b) & Gift Certificate & $\$ 75$ & $\$ 125$ & $\$ 100$ & $\$ 88$ & $\$ 40$ \\
\hline American Girl Doll & Collectible & $\$ 100$ & $\$ 90$ & $\$ 75$ & $\$ 65$ & $\$ 153$ \\
\hline DVD Player & Electronics & $\$ 100$ & $\$ 75$ & $\$ 100$ & $\$ 10$ & $\$ 120$ \\
\hline Day Spa & Gift Certificate & $\$ 200$ & $\$ 165$ & $\$ 100$ & $\$ 100$ & $\$ 54$ \\
\hline \multirow[t]{2}{*}{ TV/Video Player for Auto } & Electronics & $\$ 275$ & $\$ 200$ & $\$ 110$ & $\$ 135$ & $\$ 40$ \\
\hline & Totals & $\$ 1,255$ & $\$ 1,226$ & $\$ 825$ & $\$ 904$ & $\$ 656$ \\
\hline
\end{tabular}




\begin{tabular}{|c|c|c|c|c|}
\hline \multicolumn{5}{|c|}{ Table 2: Summary Statistics by Auction } \\
\hline Variables & First Price & Second Price & All-Pay (1) & All-Pay (2) \\
\hline Number of Potential Bidders & 31 & 30 & 15 & 21 \\
\hline Average Participation Rate & $53 \%$ & $39 \%$ & $13 \%$ & $14 \%$ \\
\hline Total revenue & $\$ 1,226$ & $\$ 825$ & $\$ 904$ & $\$ 656$ \\
\hline Revenue (dollars) & $\$ 61.3(52.64)$ & $\$ 41.25(25.89)$ & $\$ 45.2(42.92)$ & $\$ 32.8(40.24)$ \\
\hline Proportion of Items Efficiently Allocated & $.5(.51)$ & $.3(.47)$ & $.6(.50)$ & $.4(.50)$ \\
\hline Average Retail Value of Items & $\$ 62.75(65.17)$ & $\$ 62.75(65.17)$ & $\$ 62.75(65.17)$ & $\$ 62.75(65.17)$ \\
\hline Average Bid (including zeros) & $\$ 13.53(22.80)$ & $\$ 10.04(18.76)$ & $\$ 3.72(13.48)$ & $\$ 1.64(6.14)$ \\
\hline Average Bid (no zeros) & $\$ 25.42(25.98)$ & $\$ 25.53(22.36)$ & $\$ 24.43(26.50)$ & $\$ 11.51(12.38)$ \\
\hline Average Expected Bidders per Item & $23.56(24.58)$ & $18.33(13.28)$ & $8.04(5.49)$ & $17.31(15.74)$ \\
\hline Proportion of missing Expectations & $.23(.42)$ & $.12(.33)$ & $.35(.48)$ & $.33(.47)$ \\
\hline Proportion of Bids Submitted by Male & $.24(.42)$ & $.11(.31)$ & $.16(.37)$ & $.20(.40)$ \\
\hline Proportion of Bids Submitted by Female & $.71(.45)$ & $.66(.48)$ & $.74(.44)$ & $.75(.43)$ \\
\hline Proportion of Bids Submitted Jointly & $.05(.22)$ & $.22(.41)$ & $.08(.28)$ & $0(0)$ \\
\hline Proportion with HH Income $<\$ 75000$ & $.42(.50)$ & $.43(.50)$ & $.73(.46)$ & $.38(.50)$ \\
\hline Proportion with $\$ 75000<=$ HH Income $<=\$ 125000$ & $.29(.46)$ & $.37(.49)$ & $.20(.41)$ & $.33(.48)$ \\
\hline Proportion with HH Income $>\$ 75000$ & $.16(.37)$ & $.17(.38)$ & $.07(.26)$ & $.24(.44)$ \\
\hline Proportion with Missing Income & $.13(.34)$ & $.03(.18)$ & $0(0)$ & $.05(.22)$ \\
\hline Average Preschool Donations (last $6 \mathrm{mos}$ ) & $\$ 50.40(112.96)$ & $\$ 116.11(177.85)$ & $\$ 34.23(61.44)$ & $\$ 73.67(189.40)$ \\
\hline Average Future Child-Years at Preschool & $.87(1.12)$ & $1.63(1.36)$ & $.63(1.25)$ & $1.05(1.28)$ \\
\hline Proportion who are Employees or Board Members & $.29(.46)$ & $.40(.50)$ & $.53(.52)$ & $.33(.48)$ \\
\hline
\end{tabular}




\begin{tabular}{|c|c|c|}
\hline & (1) & (2) \\
\hline \multirow[t]{2}{*}{ All-Pay $\left(\right.$ Beta $\left._{1}\right)$} & 2.565 & 36.166 \\
\hline & {$[7.416]$} & {$[21.526]$} \\
\hline \multirow[t]{2}{*}{ First Price $\left(\right.$ Beta $\left._{2}\right)$} & 18.695 & 38.283 \\
\hline & {$[1.611]^{* * * *}$} & {$[9.567]^{* *}$} \\
\hline \multirow[t]{2}{*}{ Average Expected Bidders (Beta ${ }_{3}$ ) } & 0.257 & 0.83 \\
\hline & {$[0.305]$} & {$[0.649]$} \\
\hline \multirow[t]{2}{*}{ Retail Value } & 0.935 & 0.893 \\
\hline & {$[0.248]^{* *}$} & {$[0.154]^{* *}$} \\
\hline \multirow[t]{2}{*}{ Retail Value Squared } & -0.002 & -0.002 \\
\hline & {$[0.001]$} & {$[0.001]^{*}$} \\
\hline \multirow[t]{2}{*}{ All-pay*Average Expected Bidders $\left(\right.$ Beta $\left._{4}\right)$} & & -2.41 \\
\hline & & {$[0.937]^{*}$} \\
\hline \multirow[t]{2}{*}{ First Price*Average Expected Bidders (Beta $a_{5}$ ) } & & -1.046 \\
\hline & & {$[0.203]^{* *}$} \\
\hline \multirow[t]{2}{*}{ Average Preschool Donations } & & -0.02 \\
\hline & & {$[0.057]$} \\
\hline \multirow[t]{2}{*}{ Proportion of Employees or Board Members } & & -2.343 \\
\hline & & {$[6.260]$} \\
\hline \multirow[t]{2}{*}{ Proportion of Bidders who are Female } & & -2.519 \\
\hline & & {$[5.439]$} \\
\hline \multirow[t]{2}{*}{ Proportion with HH Income $<\$ 75,000 /$ year } & & -36.223 \\
\hline & & {$[18.307]$} \\
\hline \multirow[t]{2}{*}{ Average Future Child-Years } & & 11.99 \\
\hline & & {$[2.343]^{* *}$} \\
\hline \multirow[t]{2}{*}{ Average Reported Private Value } & & 0.441 \\
\hline & & {$[0.375]$} \\
\hline \multirow[t]{2}{*}{ Constant $\left(\right.$ Beta $\left._{0}\right)$} & -5.625 & -15.932 \\
\hline & {$[8.308]$} & {$[25.419]$} \\
\hline Observations & 74 & 74 \\
\hline R-squared & 0.54 & 0.61 \\
\hline
\end{tabular}

Note: Robust standard errors corrected for non-independence within auctions in brackets. * significant at $10 \%$; ** significant at $5 \%$; *** significant at $1 \%$. 


\begin{tabular}{|c|c|c|}
\hline & (1) & (2) \\
\hline \multirow[t]{2}{*}{ All-pay } & 0.094 & 0.188 \\
\hline & {$[0.045]^{* *}$} & {$[0.046]^{* * *}$} \\
\hline \multirow[t]{2}{*}{ First Price } & 0.315 & 0.335 \\
\hline & {$[0.033]^{* * *}$} & {$[0.025]^{* * *}$} \\
\hline \multirow[t]{2}{*}{ Average Expected Bidders } & -0.021 & -0.027 \\
\hline & {$[0.007]^{* * *}$} & {$[0.006]^{* * *}$} \\
\hline \multirow[t]{2}{*}{ Retail Value } & 0.002 & 0.0001 \\
\hline & {$[0.004]$} & {$[0.004]$} \\
\hline \multirow[t]{2}{*}{ Retail Value Squared } & -0.00001 & -0.000007 \\
\hline & {$[0.00002]$} & {$[0.00002]$} \\
\hline \multirow[t]{2}{*}{ Observations } & 80 & 74 \\
\hline & (all) & (positive only) \\
\hline Pseudo R-squared & 0.09 & 0.14 \\
\hline
\end{tabular}

Note: Marginal effects reported. Robust standard errors corrected for non-independence within auction in brackets. ${ }^{*}$ significant at $10 \%$; ** significant at $5 \%$; *** significant at $1 \%$. 


\begin{tabular}{|c|c|c|}
\hline & (1) & (2) \\
\hline \multirow[t]{2}{*}{ All-Pay } & -0.237 & -0.149 \\
\hline & {$[0.042]^{* * * *}$} & {$[0.053]^{* * * *}$} \\
\hline \multirow[t]{2}{*}{ First Price } & 0.132 & 0.255 \\
\hline & {$[0.060]^{* *}$} & {$[0.074]^{* * *}$} \\
\hline \multirow[t]{2}{*}{ Expected Number of Bidders } & 0.005 & 0.010 \\
\hline & {$[0.002]^{* * * *}$} & {$[0.002]^{* * *}$} \\
\hline \multirow[t]{2}{*}{ Expected Number of Bidders Missing } & 0.021 & 0.024 \\
\hline & {$[0.073]$} & {$[0.071]$} \\
\hline \multirow[t]{2}{*}{ Retail Value } & 0.001 & 0.001 \\
\hline & {$[0.0007]$} & {$[0.001]$} \\
\hline \multirow[t]{2}{*}{ Retail Value Squared } & -0.000006 & -0.000006 \\
\hline & {$[0.000002]^{* * *}$} & {$[0.000002]^{* *}$} \\
\hline \multirow[t]{2}{*}{ Female } & 0.111 & 0.126 \\
\hline & {$[0.041]^{* * *}$} & {$[0.042]^{* * * *}$} \\
\hline \multirow{2}{*}{ HH Income $<\$ 75000$} & -0.109 & -0.095 \\
\hline & {$[0.052]^{* *}$} & {$[0.054]^{*}$} \\
\hline \multirow[t]{2}{*}{$\$ 75000<=$ HH Income $<=\$ 125000$} & -0.083 & -0.070 \\
\hline & {$[0.056]$} & {$[0.056]$} \\
\hline \multirow[t]{2}{*}{ Missing Income } & 0.025 & 0.049 \\
\hline & {$[0.082]$} & {$[0.083]$} \\
\hline \multirow[t]{2}{*}{ Future Child-Years at Preschool } & 0.012 & 0.009 \\
\hline & {$[0.017]$} & {$[0.017]$} \\
\hline \multirow[t]{2}{*}{ Preschool Donations (last $6 \mathrm{mos}$ ) } & -0.0003 & -0.0003 \\
\hline & {$[0.0001]^{* *}$} & {$[0.0001]^{* * *}$} \\
\hline \multirow[t]{2}{*}{ Employee or Board Member } & 0.205 & 0.213 \\
\hline & {$[0.054]^{* * * *}$} & {$[0.055]^{* * *}$} \\
\hline \multirow[t]{2}{*}{ Reported Private Value } & 0.002 & 0.002 \\
\hline & {$[0.0005]^{* * *}$} & {$[0.0005]^{* * *}$} \\
\hline \multirow[t]{2}{*}{ No Private Value Reported } & -0.218 & -0.222 \\
\hline & {$[0.049]^{* * *}$} & {$[0.048]^{* * * *}$} \\
\hline \multirow[t]{2}{*}{ All-Pay*Expected Number of Bidders } & & -0.006 \\
\hline & & {$[0.003]^{* *}$} \\
\hline \multirow[t]{2}{*}{ First Price*Expected Number of Bidders } & & -0.007 \\
\hline & & {$[0.003]^{* * *}$} \\
\hline Observations & 1840 & 1840 \\
\hline Wald Chi-squared, p-value & $169,<0.01$ & $188,<0.01$ \\
\hline Pseudo R-squared & 0.19 & 0.20 \\
\hline
\end{tabular}




\begin{tabular}{|c|c|c|}
\hline & (1) & (2) \\
\hline \multirow[t]{2}{*}{ All-Pay $\left(\mathrm{Tau}_{1}\right)$} & -12.604 & -5.305 \\
\hline & {$[4.247]^{* * * *}$} & {$[4.971]$} \\
\hline \multirow[t]{2}{*}{ First Price $\left(\mathrm{Tau}_{2}\right)$} & 0.867 & 5.566 \\
\hline & {$[3.054]$} & {$[3.577]$} \\
\hline \multirow[t]{2}{*}{ Expected Number of Bidders $\left(\mathrm{Tau}_{3}\right)$} & 0.012 & 0.229 \\
\hline & {$[0.047]$} & {$[0.106] * *$} \\
\hline \multirow[t]{2}{*}{ Expected Number of Bidders Missing } & 3.452 & 3.588 \\
\hline & {$[3.967]$} & {$[3.879]$} \\
\hline \multirow[t]{2}{*}{ Retail Value } & 0.407 & 0.412 \\
\hline & {$[0.054]^{* * *}$} & {$[0.054]^{* * * *}$} \\
\hline \multirow[t]{2}{*}{ Retail Value Squared } & -0.001 & -0.001 \\
\hline & {$[0.0002]^{* * *}$} & {$[0.0002]^{* * * *}$} \\
\hline \multirow[t]{2}{*}{ Female } & -3.917 & -3.343 \\
\hline & {$[3.278]$} & {$[3.334]$} \\
\hline \multirow[t]{2}{*}{ HH Income $<\$ 75000$} & -9.978 & -9.210 \\
\hline & {$[3.440]^{* * * *}$} & {$[3.252]^{* * * *}$} \\
\hline \multirow[t]{2}{*}{$\$ 75000<=$ HH Income $<=\$ 125000$} & -5.896 & -5.591 \\
\hline & {$[3.544]^{*}$} & {$[3.420]$} \\
\hline \multirow[t]{2}{*}{ Missing Income } & 0.389 & 1.436 \\
\hline & {$[5.711]$} & {$[5.730]$} \\
\hline \multirow[t]{2}{*}{ Future Child-Years at Preschool } & -0.045 & -0.213 \\
\hline & {$[1.097]$} & {$[1.089]$} \\
\hline \multirow[t]{2}{*}{ Preschool Donations (last 6 mos) } & 0.028 & 0.028 \\
\hline & {$[0.016]^{*}$} & {$[0.016]^{*}$} \\
\hline \multirow[t]{2}{*}{ Reported Private Value $\left(\mathrm{Tau}_{6}\right)$} & 0.213 & 0.208 \\
\hline & {$[0.057]^{* * * *}$} & {$[0.057]^{* * *}$} \\
\hline \multirow[t]{2}{*}{ No Private Value Reported } & 6.921 & 6.546 \\
\hline & {$[4.981]$} & {$[5.004]$} \\
\hline \multirow[t]{2}{*}{ All-Pay*Expected Number of Bidders $\left(\mathrm{Tau}_{4}\right)$} & & -0.421 \\
\hline & & {$[0.132]^{* * * *}$} \\
\hline \multirow[t]{2}{*}{ First Price*Expected Number of Bidders (Tau $\left.{ }_{5}\right)$} & & -0.233 \\
\hline & & {$[0.105]^{* *}$} \\
\hline \multirow[t]{2}{*}{ Constant $\left(\mathrm{Tau}_{0}\right)$} & 8.508 & 3.153 \\
\hline & {$[4.277]^{* *}$} & {$[4.590]$} \\
\hline Observations & 648 & 648 \\
\hline F statistic, $\mathrm{p}$-value & $17,<0.01$ & $16,<0.01$ \\
\hline R-squared & 0.47 & 0.48 \\
\hline
\end{tabular}




\begin{tabular}{|c|c|c|c|c|c|c|}
\hline & \multicolumn{2}{|c|}{ Model (1) } & \multicolumn{2}{|c|}{ Model (2) } & \multicolumn{2}{|c|}{ Model (3) } \\
\hline & Participation & Bid & Participation & Bid & Participation & Bid \\
\hline \multirow[t]{2}{*}{ All-Pay } & -0.239 & -17.559 & -0.169 & -8.396 & -0.149 & -6.003 \\
\hline & {$[0.026]^{* * * *}$} & {$[3.705]^{* * * *}$} & {$[0.039]^{* * * *}$} & {$[4.133]^{* * *}$} & {$[0.040]^{* * * *}$} & {$[3.779]$} \\
\hline \multirow[t]{2}{*}{ First Price } & 0.138 & 1.954 & 0.254 & 8.873 & 0.255 & 6.114 \\
\hline & {$[0.030]^{* * * *}$} & {$[1.982]$} & {$[0.043]^{* * * *}$} & {$[3.267]^{* * *}$} & {$[0.044]^{* * * *}$} & {$[3.001]^{* * *}$} \\
\hline \multirow[t]{2}{*}{ Expected Number of Bidders } & 0.006 & 0.078 & 0.010 & 0.398 & 0.010 & 0.250 \\
\hline & {$[0.001]^{* * * *}$} & {$[0.046]^{*}$} & {$[0.001]^{* * * *}$} & {$[0.116]^{* * * *}$} & {$[0.001]^{* * * *}$} & {$[0.106]^{* *}$} \\
\hline \multirow[t]{2}{*}{ Expected Number of Bidders Missing } & -0.099 & 3.335 & -0.098 & 3.580 & 0.024 & 3.568 \\
\hline & {$[0.032]^{* * * *}$} & {$[2.859]$} & {$[0.032]^{* * * *}$} & {$[2.781]$} & {$[0.041]$} & {$[2.444]$} \\
\hline \multirow[t]{2}{*}{ Retail Value } & 0.002 & 0.507 & 0.002 & 0.512 & 0.001 & 0.415 \\
\hline & {$[0.001]^{* * * *}$} & {$[0.044]^{* * *}$} & {$[0.001]^{* * *}$} & {$[0.044]^{* * * *}$} & {$[0.001]^{*}$} & {$[0.041]^{* * * *}$} \\
\hline \multirow[t]{2}{*}{ Retail Value Squared } & -0.000007 & -0.001 & -0.000007 & -0.001 & -0.000006 & -0.001 \\
\hline & {$[0.000]^{* * * *}$} & {$[0.0002]^{* * *}$} & {$[0.000]^{* * * *}$} & {$[0.0002]^{* * *}$} & {$[0.000]^{* * * *}$} & {$[0.0001]^{* * *}$} \\
\hline \multirow[t]{2}{*}{ Female } & 0.108 & -1.832 & 0.121 & -1.025 & 0.126 & -3.077 \\
\hline & {$[0.024]^{* * * *}$} & {$[1.858]$} & {$[0.024]^{* * * *}$} & {$[1.895]$} & {$[0.024]^{* * * *}$} & {$[1.786]^{*}$} \\
\hline \multirow[t]{2}{*}{ HH Income $<\$ 75000$} & -0.083 & -11.966 & -0.071 & -10.890 & -0.095 & -9.451 \\
\hline & {$[0.032]^{* * * *}$} & {$[2.249]^{* * * *}$} & {$[0.033]^{* *}$} & {$[2.222]^{* * * *}$} & {$[0.034]^{* * * *}$} & {$[2.106]^{* * * *}$} \\
\hline \multirow[t]{2}{*}{$\$ 75000<=$ HH Income $<=\$ 125000$} & -0.066 & -8.076 & -0.053 & -7.517 & -0.070 & -5.931 \\
\hline & {$[0.034]^{* * *}$} & {$[2.549]^{* * * *}$} & {$[0.035]$} & {$[2.486]^{* * * *}$} & {$[0.035]^{* * *}$} & {$[2.352]^{* * * *}$} \\
\hline \multirow[t]{2}{*}{ Missing Income } & 0.041 & 2.440 & 0.064 & 3.849 & 0.049 & 1.444 \\
\hline & {$[0.056]$} & {$[3.185]$} & {$[0.057]$} & {$[3.184]$} & {$[0.058]$} & {$[2.947]$} \\
\hline \multirow[t]{2}{*}{ Future Child-Years at Preschool } & 0.016 & -0.099 & 0.014 & -0.343 & 0.009 & -0.243 \\
\hline & {$[0.010]$} & {$[0.635]$} & {$[0.010]$} & {$[0.636]$} & {$[0.010]$} & {$[0.594]$} \\
\hline \multirow[t]{2}{*}{ Preschool Donations (last 6 mos) } & -0.0003 & 0.030 & -0.0003 & 0.030 & -0.0003 & 0.028 \\
\hline & {$[0.0001]^{* * *}$} & {$[0.005]^{* * * *}$} & {$[0.0001]^{* * * *}$} & {$[0.005]^{* * *}$} & {$[0.0001]^{* * * *}$} & {$[0.005]^{* * *}$} \\
\hline \multirow[t]{2}{*}{ Employee or Board Member } & 0.197 & & 0.206 & & 0.213 & \\
\hline & {$[0.028]^{* * * *}$} & & {$[0.028]^{* * * *}$} & & {$[0.029]^{* * * *}$} & \\
\hline \multirow[t]{2}{*}{ All-Pay*Expected Number of Bidders } & & & -0.005 & -525 & -0.006 & -0.432 \\
\hline & & & {$[0.002]^{* *}$} & {$[0.150]^{* * *}$} & {$[0.002]^{* * * *}$} & {$[0.141]^{* * * *}$} \\
\hline \multirow[t]{2}{*}{ First Price*Expected Number of Bidders } & & & -0.007 & -0.355 & -0.007 & -0.250 \\
\hline & & & {$[0.002]^{* * *}$} & {$[0.116]^{* * *}$} & {$[0.002]^{* * *}$} & {$[0.107]^{* *}$} \\
\hline \multirow[t]{2}{*}{ Reported Private Value } & & & & & 0.002 & 0.212 \\
\hline & & & & & {$[0.0004]^{* * *}$} & {$[0.026]^{* * *}$} \\
\hline \multirow[t]{2}{*}{ No Private Value Reported } & & & & & -0.222 & 5.717 \\
\hline & & & & & {$[0.029]^{* * * *}$} & {$[3.832]$} \\
\hline Lambda (inverse Mills Ratio), p-value & \multicolumn{2}{|c|}{$8.158,0.095$} & \multicolumn{2}{|c|}{$8.164,0.092$} & \multicolumn{2}{|c|}{$1.546,0.731$} \\
\hline rho & \multicolumn{2}{|c|}{0.416} & \multicolumn{2}{|c|}{0.420} & \multicolumn{2}{|c|}{0.089} \\
\hline Observations & 1840 & 1192 & 1840 & 1192 & 1840 & 1192 \\
\hline Wald Chi-squared, p-value & 732 & 0.01 & 761 & 0.01 & 926 & 0.01 \\
\hline
\end{tabular}




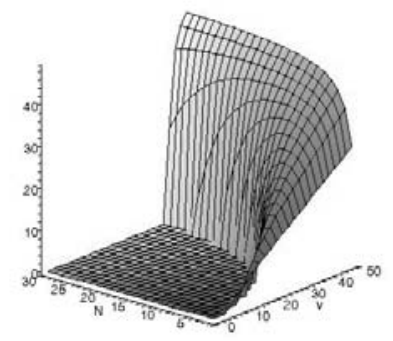

(a) Bids versus $v$ and $N$

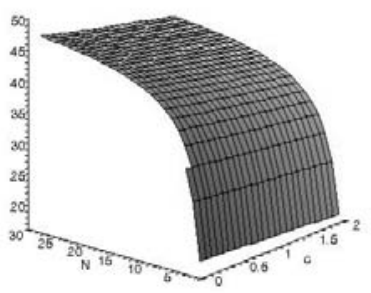

(b) Revenues versus $v$ and $N$

Figure 1: Bids and Revenues in the First Price Auction with Participation Costs

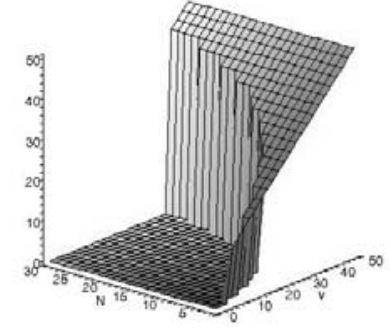

(a) Bids versus $v$ and $N$

Figure 2: Bids and Revenues in the Second Price Auction with Participation Costs

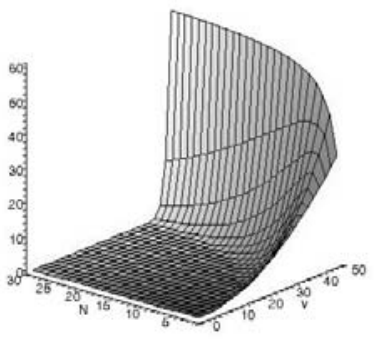

(a) Bids versus $v$ and $N$

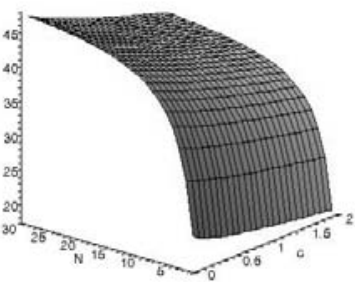

(b) Revenues versus $v$ and $N$

Figure 3: Bids and Revenues in the All-pay Auction with Participation Costs 